\title{
HANS KÖRNER
}

\section{Frömmigkeit und Moderne. Zu einem Schwerpunkt in Forschung und Lehre am Seminar für Kunstgeschichte}

Architektur des 20. Jahrhunderts - damit verbindet man zuallererst den modernen Wohn-, Büro-, Geschäfts- und Industriebau, Bauten für die Anforderung des Verkehrs oder Sportanlagen. Der Kirchenbau des 20. Jahrhunderts wird dagegen häufig nur als Seitenweg der Avantgardearchitektur betrachtet, als Randphänomen. Dieses Urteil ist ungerecht und historisch nicht haltbar. Gerade im Kirchenbau kam es zu außerordentlichen und wegweisenden Lösungen. Eher war das Experimentierfeld, das die Bauaufgabe „Kirche“ eröffnete, größer als bei anderen funktional stärker gebundenen Bauaufgaben, und entsprechend eindrucksvoll ist die Originalität der gefundenen Lösungen.

Auf dem wichtigen Beitrag, den die Kirchenbaumeister des 20. Jahrhunderts für die Ausbildung einer modernen Architektur geleistet haben, liegt ein Schwerpunkt des Seminars für Kunstgeschichte. Ohne die nationale und internationale Dimension des Themas zu vernachlässigen, ist es uns ein Anliegen, darauf aufmerksam zu machen, dass im Besonderen im heutigen Bundesland Nordrhein-Westfalen herausragende Leistungen auf dem Gebiet des modernen Sakralbaus gelungen sind. Leider muss man heute dringlicher denn je auf diesen Umstand hinweisen. Nach dem beispiellosen Bauboom in der frühen Nachkriegszeit ist heute der moderne Kirchenbau eine bedrohte Spezies. Die Umwidmung überflüssig gewordener Kirchen beschäftigt derzeit die Phantasie der Architekten mehr als der Bau neuer Kirchen. Und man wird in manchen Fällen noch über den Akt der Entweihung dankbar sein dürfen, wenn dieser wenigstens den Abriss verhindern hilft. Für Klagen über die zunehmende Marginalisierung des Christentums im alltäglichen Lebensvollzug sind Kunsthistoriker freilich nicht zuständig. Kunsthistoriker haben auf die Schönheit dessen hinzuweisen, was auf dem Gebiet des Sakralbaus der Zwischenkriegszeit und der frühen Nachkriegszeit entstanden ist, auf die in manchen Fällen selbst von den Pfarrern verkannte Schönheit, die derzeit eine bedrohte Schönheit ist. Wir sehen unser Ziel deshalb auch darin, deutlich zu machen, was es zu bewahren gilt.

Forschung und Lehre müssen keine Gegensätze sein; sie können - sie sollten - sich wechselseitig befruchten. Gelegentlich - und diese Gelegenheiten sind gesuchte Gelegenheiten am Seminar für Kunstgeschichte - verschmelzen Forschung und Lehre in Projektseminaren. Eine Ausstellung zum Thema „Frömmigkeit und Moderne“, die das ClemensSels-Museum, Neuss, im Herbst 2008 zeigte, war von Lehrenden und Studierenden des Seminars für Kunstgeschichte vorbereitet und über alle Phasen eines Ausstellungsprojekts - von der Konzeption und der wissenschaftlichen Bearbeitung der Objekte über die Organisation des Leihverkehrs bis zur Erstellung eines Ausstellungskatalogs und der Hängung der Exponate in den Räumen des Museums - selbständig verwirklicht worden. Aus- 
stellung und Ausstellungskatalog erwuchsen aus einem Projektseminar, das Jürgen Wiener und der Verfasser im Sommersemester 2007 am Seminar für Kunstgeschichte angeboten haben.

Die Ausstellung präsentierte Hauptwerke der modernen Sakralarchitektur an Rhein und Ruhr in Form von Architekturaufnahmen. Gemeinsam mit den Studierenden wählten wir als Exponate Fotografien aus, die möglichst zeitnah zu der Entstehung der Kirchenbauten aufgenommen wurden. Dies nicht allein deshalb, weil Architektur (will man sich nicht auf Planmaterial und Modelle beschränken) nun einmal nicht ausstellbar ist. Fotografien sind immer auch schon Interpretationen und geben dem Betrachter Seh-Vorgaben. Insofern liefern sie ein in seiner historischen Relevanz bislang noch unzureichend ausgeschöpftes Material für die historische Wahrnehmung von Architektur. Die Ausstellung und der begleitende Katalog machten sichtbar, wie und mit welchen Mitteln die Fotografie christliche Sakralbauten des 20. Jahrhunderts interpretierte; sie lieferten darüber hinaus Hinweise darauf, in welchem Maße Sakralarchitektur der Moderne von sich her schon den ,fotografischen Blick“ mit einkalkulierte. Dass die Rolle der Fotografie für die Wahrnehmung und Wertschätzung moderner Sakralarchitektur eine gewichtige war, lässt sich bereits aus dem Wort des katholischen Kirchenbaumeisters Rudolf Schwarz, der der Wahrnehmung von Architektur über das Medium der Fotografie ansonsten durchaus skeptisch gegenüberstand, erschließen: „Was wäre die Architektur ohne Fotografen?“”

Weder als Forschungsschwerpunkt noch als Thema von gemeinsam mit Studierenden betriebenen Projekten ist das Thema „Moderne Sakralkunst“ abgeschlossen. Gefördert aus zentralen Mitteln des Rektorats bereiteten Jürgen Wiener und der Verfasser eine wissenschaftliche Tagung zum Thema „Liturgie als Bauherr?“ vor. Der Tagung lief ein Aufbau/Masterseminar im Sommersemester 2009 voraus. Auch dieses Aufbau-/Masterseminar wurde als Projektseminar durchgeführt. Im Fokus des Projekts stand die Frage nach den Wechselbeziehungen zwischen Liturgie, Baugestalt und Kirchenausstattung. Wie in jedem „,normalen“ Seminar wurden Referate gehalten und schriftliche Studienarbeiten abgeliefert, doch war dies nur das Zwischenziel. Das Seminar mündete in die mehrtägige Tagung auf Schloss Mickeln (10. bis 12. Juli 2009), bei der etablierte und renommierte Wissenschaftler Vorträge zum Thema hielten. Daneben wurden die besten studentischen Seminararbeiten vorgetragen; sie werden mit den Beiträgen der Gastwissenschaftler in einem Tagungsband publiziert werden. Auf der Tagung waren die Studierenden nicht Lernende, sondern Kolleginnen und Kollegen, hatten also Gelegenheit, sich schon im Studium auf dem Parkett des Wissenschaftsbetriebs zu bewegen und bewähren.

\section{Moderne christliche Kunst.}

\section{Voraussetzungen und Anfänge im 18. und 19. Jahrhundert}

Blumen-, Frucht- und Dornenstücke oder Ehestand, Tod und Hochzeit des Armenadvokaten F. St. Siebenkäs im Reichsmarktflecken Kuhschnappel. Der umfangreiche Roman von Jean Paul, der in einer ersten Auflage 1796 veröffentlicht wurde, ist so weitschweifig wie sein Titel, und er ist in seiner Empfindsamkeit, seinem Witz und seiner Ironie so umständlich wie dieser Titel. Jean Paul fügte dem Roman ein „Erstes Blumenstück“ ein, dessen Entwurf er bereits im Revolutionsjahr 1789 verfasst hatte. Entgegen der verharmlosenden Bezeichnung bringt dieses „Blumenstück“ eine Kälte in den Text, die noch heutige Leser 
nachhaltig zu erschrecken vermag. Es ist die „Rede des toten Christus vom Weltgebäude herab, dass kein Gott sei“.

Im Anschluss an den Bericht vom nächtlichen Friedhofsbesuch seines Helden erzählt Jean Paul einen Albtraum. Schon im ersten Satz entschuldigt sich der Autor: „Das Ziel dieser Dichtung ist die Entschuldigung ihrer Kühnheit“. Und er versichert dem Leser im Vorfeld schon sein eigenes Erschrecken über den Traum:

Ebenso erschrak ich über den giftigen Dampf, der dem Herzen dessen, der zum erstenmal in das atheistische Lehrgebäude tritt, erstickend entgegenzieht [ . . ]. Das ganze geistige Universum wird durch die Hand des Atheismus zersprengt und zerschlagen [. . . ]. Niemand ist im All so sehr allein als ein Gottesleugner - er trauert mit seinem verwaisten Herzen, das den größten Vater verloren, neben dem unermesslichen Leichnam der Natur [. . . . Die ganze Welt ruht vor ihm wie die große, halb im Sande liegende ägyptische Sphinx aus Stein; und das All ist die kalte eiserne Maske der gestaltlosen Ewigkeit. ${ }^{1}$

Jean Paul wirft pädagogische Erwägungen für sein literarisches Wagnis in die Waagschale:

Auch habe ich die Absicht, mit meiner Dichtung einige lesende oder gelesene Magister in Furcht zu setzen, da wahrlich diese Leute jetzo [...] das Dasein Gottes so kaltblütig und kaltherzig erwägen, als ob vom Dasein des Kraken und Einhorns die Rede wäre. ${ }^{2}$

Aber keine entschuldigende Vorbemerkung, keine pädagogische Begründung nimmt der Traumerzählung ihren Schrecken. Der Autor erinnert sich:

Ich lag an einem Sommerabende vor der Sonne auf einem Berge und entschlief. Da träumte mir, ich erwachte auf dem Gottesacker. Die abrollenden Räder der Turmuhr, die eilf Uhr schlug, hatten mich erweckt. Ich suchte im ausgeleerten Nachthimmel die Sonne, weil ich glaubte, eine Sonnenfinsternis verhülle sie mit dem Mond. Alle Gräber waren aufgetan, und die eisernen Türen des Gebeinhauses gingen unter unsichtbaren Händen auf und zu. An den Mauern flogen Schatten, die niemand warf, und andere Schatten gingen aufrecht in der bloßen Luft. In den offenen Särgen schlief nichts mehr als die Kinder. [.. .] Alle Schatten standen um den Altar, und allen zitterte und schlug statt des Herzens die Brust. [...] Jetzo sank eine hohe edle Gestalt mit einem unvergänglichen Schmerz aus der Höhe auf den Altar hernieder, und alle Toten riefen: ,Christus! ist kein Gott?‘. Er antwortete: ,Es ist keiner. 'Der ganze Schatten jedes Toten erbebte [...]. Christus fuhr fort: ,Ich ging durch die Welten, ich stieg in die Sonnen und flog mit den Milchstraßen durch die Wüsten des Himmels; aber es ist kein Gott. Ich stieg herab, soweit das Sein seine Schatten wirft, und schauete in den Abgrund und rief: ,Vater, wo bist du?' aber ich hörte nur den ewigen Sturm, den niemand regiert, und der schimmernde Regenbogen aus Wesen stand ohne Sonne, die ihn schuf, über dem Abgrunde und tropfte hinunter. Und als ich aufblickte zur unermesslichen Welt nach dem göttlichen Auge, starrte sie mich mit einer leeren Augenhöhle an; und die Ewigkeit lag auf dem Chaos und zernagte es und wiederkäuete sich. - Schreiet fort, Misstöne, zerschreiet die Schatten; denn Er ist nicht! ' Die entfärbten Schatten zerflatterten, wie weißer Dunst, den der Frost gestaltet, im warmen Hauche zerrinnt; und alles wurde leer. Da kamen, schrecklich für das Herz, die gestorbenen Kinder, die im Gottesacker erwacht waren, in den Tempel und warfen sich vor die hohe Gestalt am Altare und sagten: ,Jesus! haben wir keinen Vater?` - Und er antwortete mit strömenden Tränen: ,Wir sind alle Waisen, ich und ihr, wir sind ohne Vater. ' Da kreischten die Mißtöne heftiger - die zitternden Tempelmauern rückten auseinander - und der Tempel und die

\footnotetext{
1 Jean Paul (1987: 274f.).

2 Jean Paul (1987: 275).
} 
Kinder sanken unter - und die ganze Erde und die Sonne sanken nach - und das ganze Weltgebäude sank mit seiner Unermesslichkeit vor uns vorbei - und oben am Gipfel der unermesslichen Natur stand Christus und schauete in das mit tausend Sonnen durchbrochene Weltgebäude herab $[\ldots] .^{3}$

Erleichtert schildert Jean Paul sein Erwachen:

Meine Seele weinte vor Freude, daß sie wieder Gott anbeten konnte - und die Freude und das Weinen und der Glaube an ihn waren das Gebet. [. . .] und von der ganzen Natur um mich flossen friedliche Töne aus, wie von fernen Abendglocken. ${ }^{4}$

Andere Texte hätten diesen Beitrag einleiten können, Texte, die schon vor Jean Paul die Botschaft verkünden (oder zumindest andeuten): Gott ist tot. Die französische Aufklärung ging in Texten wie dem „L'homme machine“ La Mettries und seiner These, dass der Mensch einschließlich dessen, was man einmal seine Seele nannte, nur das Räderwerk einer mehr oder weniger komplizierten Maschine sei, bereits bis ans Ende. ${ }^{5}$ Und eine andere Traumerzählung, „Rêve de d'Alembert“ („D’Alemberts Traum“) von Denis Diderot, in dem Existenz nach dem Tod nur noch als Transformation in andere Zustände der Materie gedacht wird, ist bereits atheistischer Materialismus in Reinform. ${ }^{6}$

Wenn Historiker, Kulturhistoriker und Kunsthistoriker die Moderne mit der Aufklärung beginnen lassen, dann auch wegen dieser erst jetzt ganz gewonnenen Möglichkeit, eine gottlose Welt zu denken und zu erleben. Wenn nicht La Mettrie, Diderot und keiner der anderen radikalen französischen Aufklärer an den Beginn dieses Aufsatzes gestellt wurde, sondern das befremdliche „Blumenstück“ aus Jean Pauls Siebenkäs, dann des Schocks wegen, mit dem bei Jean Paul die Vision einer gottverlassenen Welt in das zumindest nach außen hin beschauliche Kuhschnappel einbricht. Insofern die ästhetische Inszenierung des Schocks ihrerseits ein Signum der Moderne ist, darf Jean Pauls „Rede des toten Christus vom Weltgebäude herab, dass kein Gott sei“ in zweifacher Hinsicht als ein Gründungstext der Moderne gelten.

Wenn also Atheismus und Moderne miteinander zu tun haben, und sie haben miteinander zu tun, dann ist das Phänomen einer genuin modernen christlichen Kunst nicht selbstverständlich, wenn man es nicht als Rückzugsgefecht des Christentums in und vor der Moderne, sondern als lebendige und für beide fruchtbare Begegnung beschreiben will.

\section{„Gültige Gestalt aus der Kraft der Not““}

Die Krisen, in die die Aufklärung das Christentum geführt hatte, waren zugleich die Geburtswehen eines neuen, eines modernen Christentums. Der Reichtum der Amtskirche war ein Hauptangriffsziel der Aufklärung gewesen und der aufklärerische Vorwurf, Religion im Allgemeinen, die christliche Religion im Besonderen sei Priesterbetrug, beinhaltete immer auch den Vorwurf, dass dieser Priesterbetrug von ökonomischen Absichten getragen sei und der Stabilisierung von Herrschaftsverhältnissen diene. In der Französischen Revolution kehrten sich die Verhältnisse um. Die Kirchengüter wurden verstaatlicht; Robespierre führte den Kult des „Höchsten Wesens“ ein, ein aufklärerischer Religionsersatz,

\footnotetext{
3 Jean Paul (1987: 276-278).

4 Jean Paul (1987: 279f.).

5 Vgl. La Mettrie (1774: III).

6 Vgl. Diderot (1875).
} 
der dem Gespenst des Christentums den Garaus machen sollte. So geschah es, dass der Katholizismus im katholischen Frankreich zumindest zeitweise in den Untergrund gedrängt wurde, bevor Napoleon aus politischer Berechnung wieder Zugeständnisse an die christliche Tradition und an die römische Kirche machte.

Von einer dieser Stätten, an denen die katholische Kirche wieder in den Untergrund zurückkehrte, aus dem sie in der Antike aufgestiegen war, sei kurz die Rede. Als die Pariser Revolutionäre den König aufs Schafott gebracht hatten und als die antikirchliche Stoßrichtung der Revolution offenkundig wurde, erhoben sich die der Krone und der Kirche treuen Bauern der Vendée unter Führung von Landadeligen. Es kam zum Bürgerkrieg, in dem die anfänglich unterschätzten Aufständischen unerwartete Erfolge erzielten. Zur Strafe und zur Abschreckung sandte die französische Zentralregierung die „Colonnes infernales“ des Generals Turreau, die gnadenlos die Dörfer verwüsteten und Männer, Frauen und Kinder hinschlachteten. Vor dieser Todesschwadron flohen Viele und verbargen sich im Wald von Grasla. In diesem damals unerschlossenen Waldgebiet lebten von Januar bis zum Sommer des Jahres 1794 2.000 Menschen unter kaum vorstellbaren Bedingungen. Aus Holz, Lehm und Schilf bauten sie für sich und ihre Tiere Hütten, in denen sie nicht nur die Entdeckung durch die Revolutionstruppen, sondern neben den Unbilden des Wetters auch die zahlreichen Schlangen zu fürchten hatten.

Diese Siedlung inmitten des Waldes ist heute teilweise rekonstruiert worden. Rekonstruiert wurde auch das sakrale Zentrum dieser Siedlung; eine Lichtung mit grob gezimmerten Holzbänken für die Gläubigen; ein Holzverschlag, der auf die Lichtung hin geöffnet ist, mit einem einfachen Kreuz auf dem Dachfirst (Abb. 1); eine schlichte Holzkiste als Altar (Abb. 2).

Es führt kein direkter Weg von dieser Notkirche im Wald von Grasla hin zu dem neuen Armutsideal, dem sich zahlreiche Kirchenbauten des 20. Jahrhunderts verpflichtet fühlen werden. Einen indirekten Weg gibt es freilich sehr wohl. Durch solche und andere Manifestation eines im Untergrund gelebten Christentums konnte man sich dem Anfang wieder ganz nahe fühlen. Das Frühchristentum, staatlich verfolgt, im Untergrund praktiziert; eine Religiosität ohne aufwändige Kirchenbauten, eine Religiosität, deren Armut ihren Reichtum ausmacht - dieses ferne Ideal hatten Not und Unterdrückung wieder nahe gebracht.

Für zahlreiche Kirchenbauten der Jahre nach 1945 wird dieses Ideal zum Leitbild werden. „Notkirchen“ stiegen zum Ausdruck eines neuen, von Leid, Zerstörung und Schuld geprägten religiösen Selbstverständnisses auf. Otto Bartning, der ab 1948 im Rahmen des von Spenden aus den USA und der Schweiz finanzierten „Notkirchenprogramms“ in Fertigbauweise 47 Notkirchen in Deutschland errichtete (Abb. 3, 4), betonte die Gültigkeit und Dauerhaftigkeit des Vorläufigen:

Jede echte Kirche ist Bekenntnis und Überwindung der inneren Not. Diese hier sind zugleich Bekenntnis der äußeren Not. Also nicht Notbehelf, sondern Notkirche in zwiefachem Sinne. ${ }^{7}$

Mit den Trümmersteinen des Bombenkrieges fachte die selbstlos ihren Anteil am Bau der Kirche leistende Bevölkerung das vorgefertigte und montierte Holzgerüst der Notkirchen Otto Bartnings aus. Die Nutzung des Trümmermaterials war ein Gebot der Sparsamkeit, es war für Bartning darüber hinaus das Material, das denen zukomme, die als „Kenner der Wüste, der äußeren wie der inneren“ eine neue Gemeinschaft bilden, sich „,in

\footnotetext{
7 Die 48 Notkirchen in Deutschland (1949: o. S.).
} 


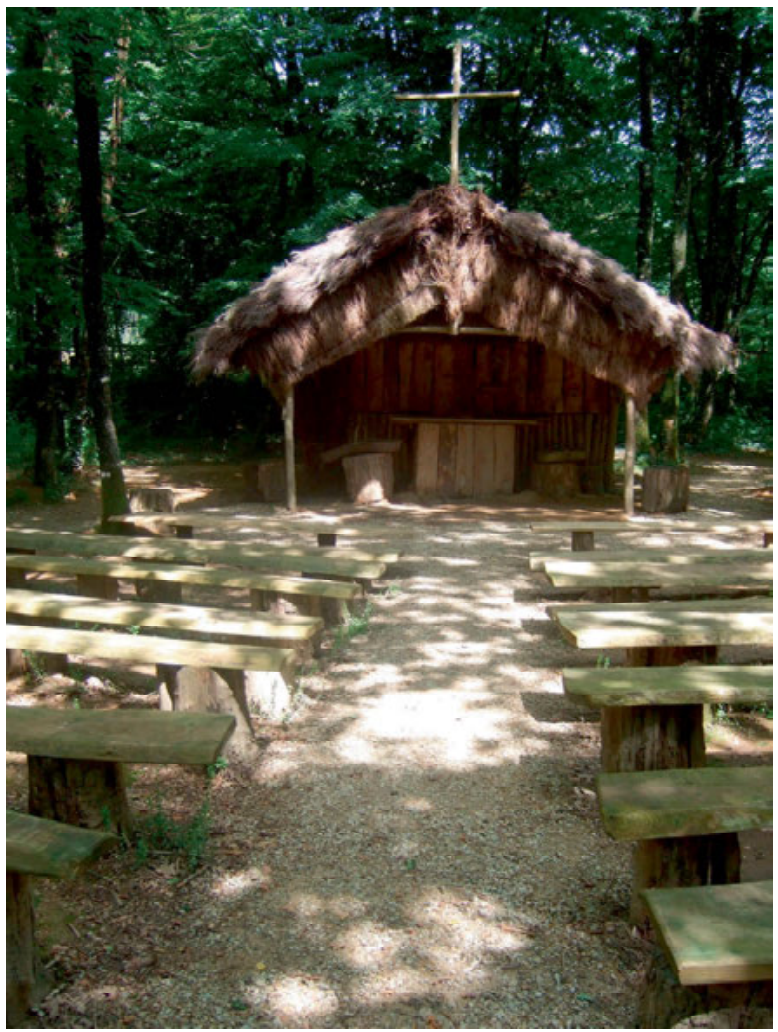

Abb. 1: Wald von Grasla, Kirche und Bankreihen, 1794, Rekonstruktion

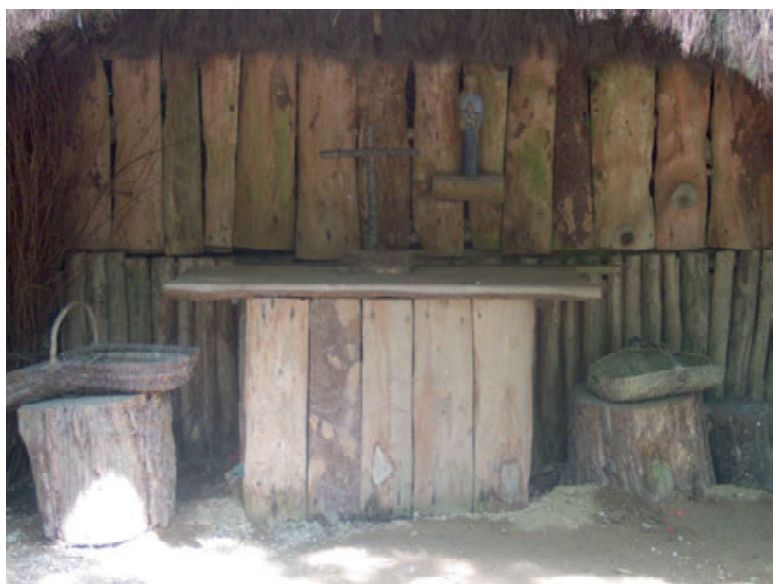

Abb. 2: Wald von Grasla, Kirche (Altar), 1794, Rekonstruktion 


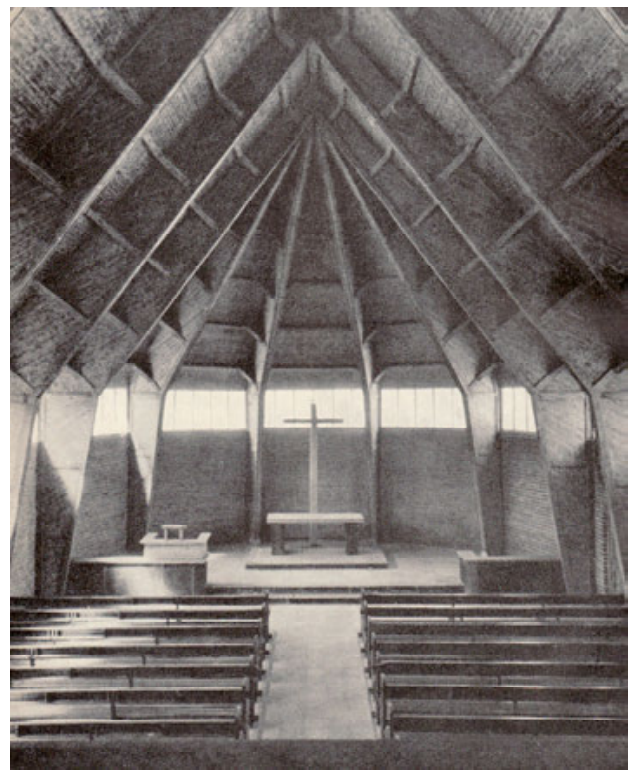

Abb. 3: Otto Bartning, Köln-Mühlheim, Notkirche, 1949

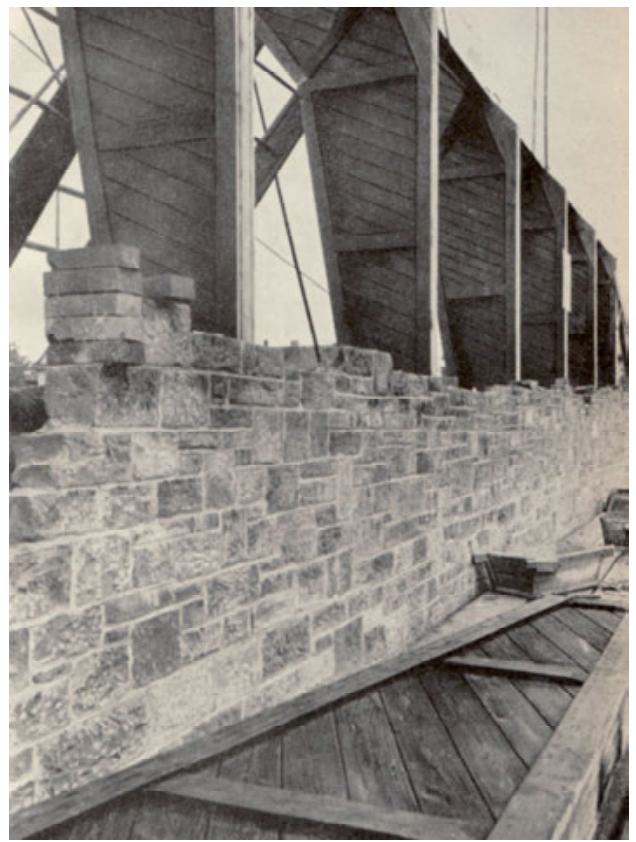

Abb. 4: Otto Bartning, Notkirche im Aufbau 
der Wüste [...] ein Zelt bauen“ wollen. Insofern steht der Trümmerstein für das Vorläufige, das Provisorische, den armseligen Anfang, und eben deshalb ist das Vorläufige auch das Bleibende: „Wir wissen, daß Notkirche nicht notdürftigen Behelf, sondern neue und gültige Gestalt aus der Kraft der Not bedeutet. “8

Schon die frühe Verwertung der Trümmersteine war also mit Bedeutung aufgeladen; die Bruchsteine aber, aus denen die 1967, ein Jahr vor Emil Steffanns Tod, fertiggestellte Hedwigskirche in Köln-Höhenhaus gemauert wurde, konnten gewiss nicht mehr von einem nahe gelegenen Trümmerhaufen herangeschafft werden (Abb. 5). Der Trümmerstein war zu einem erlesenen Baumaterial geworden. Für den vom Protestantismus zum Katholizismus konvertierten Architekten Emil Steffann war die „Armut“, die in „Schutt und Trümmern“ der Städte der Nachkriegszeit begegnete, ein Wert, den es zu erkennen und zu nutzen galt:

Betonbrocken, Mauer- und geborstene Natursteine könnten zum lebendigen Gewand eines Neuen werden, welches die Zerstörungen, die uns trafen, nicht einfach fortschafft, sondern überwindet. Ein Neues müßte auferstehen, welches dem großen Anruf nicht ausweicht, das in der Armut gründet [und das den; d. Verf.] auch heute noch in ihr verborgenen Adel findet, die Arm-Seligkeit in des Wortes ursprünglicher, ganz neuer, beglückender Bedeutung. ${ }^{9}$

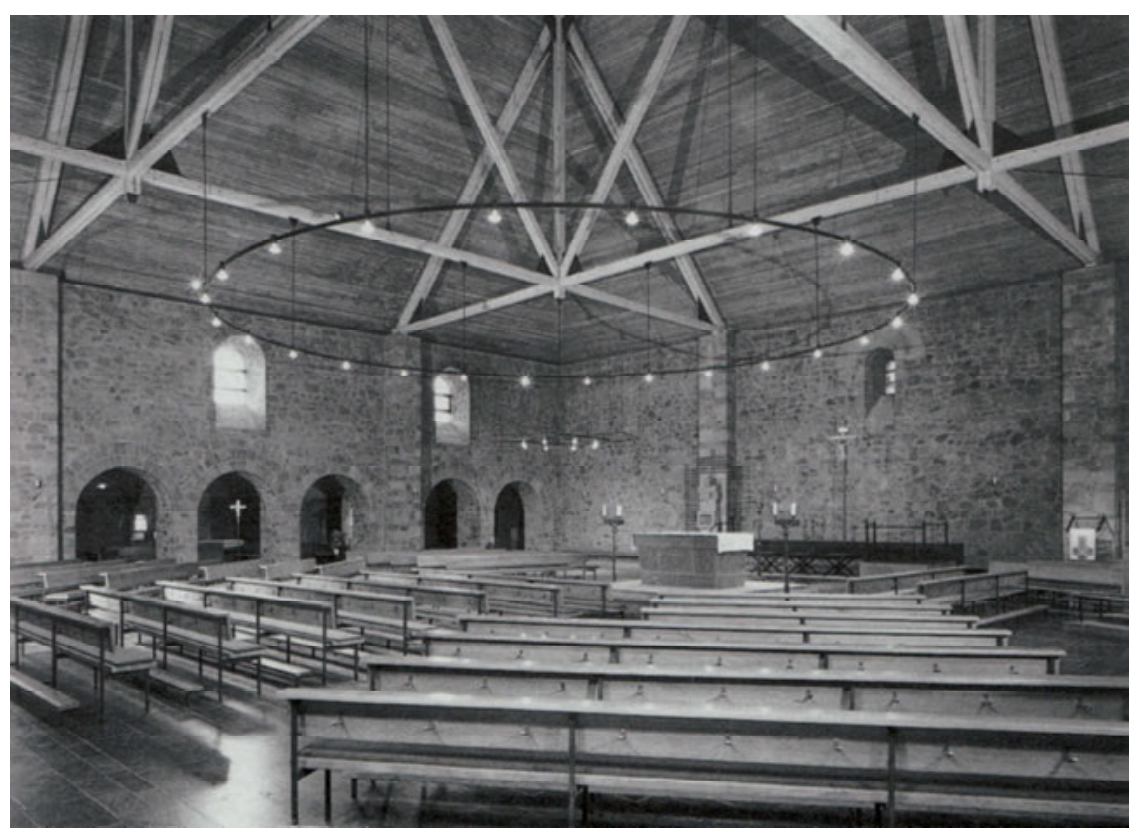

Abb. 5: Emil Steffann, Köln-Höhenhaus, St. Hedwig, 1966-1967

\footnotetext{
8 Bartning (1958: 100). Vgl. Körner (2008: 44).

9 Steffann (1980: 107).
} 


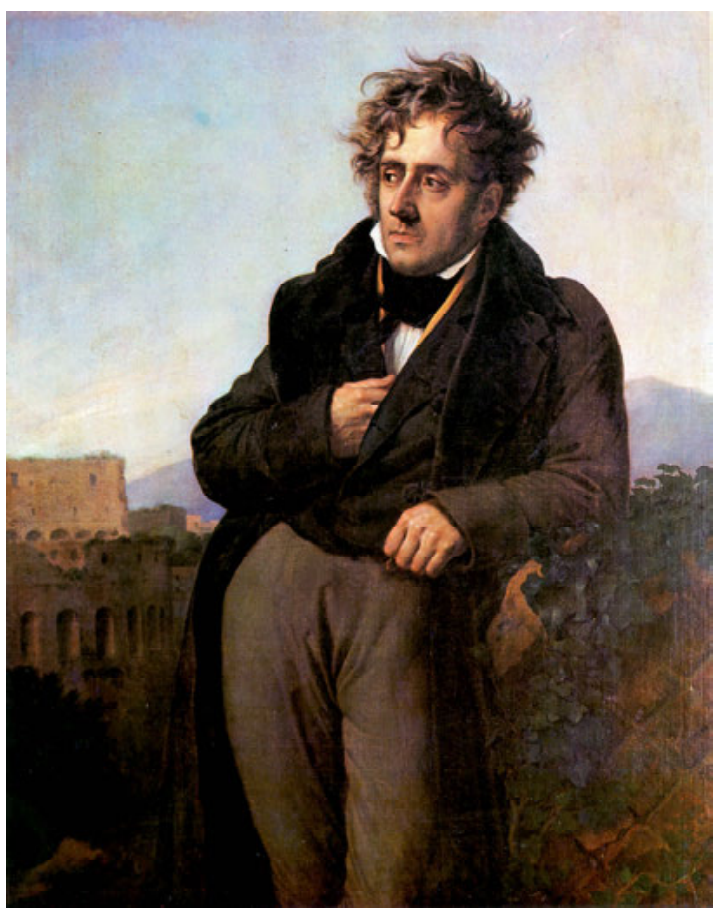

Abb. 6: Anne-Louis Girodet-Trioson, Bildnis Graf François René de Chateaubriand, Salon de 1810, Saint-Malô, Musée

\section{„Die Schönheiten der christlichen Religion““}

Eine weitere Wurzel einer neuen christlichen Kunst (und einer neuen christlichen Spiritualität) ist die ästhetische Erfahrung des Heiligen. Graf François René de Chateaubriand (Abb. 6) würdigte literarisch den verzweifelten Kampf der Chouans - so nannte man die Aufständischen in der Vendée und in der Bretagne. Derselbe Chateaubriand war maßgeblich mitverantwortlich für eine neue ästhetisch formatierte Religiosität. 1802 erschien Chateaubriands Hauptwerk, Le Génie du Christianisme ou Beautés de la Religion Chrétienne (Der Geist des Christentums oder Schönheiten der christlichen Religion). Bezeichnend ist bereits der Buchtitel, weil er deutlich zu erkennen gibt, dass es dem Autor primär nicht darum zu tun war, auf gelehrte theologische oder philosophische Weise und schon gar nicht mit dogmatischen Argumenten die Überlegenheit des Christentums gegenüber anderen Religionen oder die Wahrheit der christlichen Offenbarung dem Atheismus gegenüber zu beweisen. Nicht die Wahrheit des Christentums wurde von Chateaubriand in den Vordergrund gestellt, sondern seine Schönheit. Chateaubriand zufolge ist das Christentum poetisch, natürlich, rührend, und ist solcherart stete Inspirationsquelle für die Künste. 
Die Bibel würdigte Chateaubriand folglich auch und vor allem als Werk der Dichtung und stellte sie als solches weit über alles andere, auch über die Werke Homers. ${ }^{10}$

„Um mit der Regel zusammen das Beispiel zu geben“ und „,gottlose Dichtungen und Romane mit frommen zu bekämpfen" "11, fügte Chateaubriand seinem Traktat zwei Novellen ein: den René, der in bemerkenswerter Offenheit Schuld und Sühne einer inzestuösen Bruder-Schwester-Liebe schildert (und in dem François René de Chateaubriand Autobiographisches mitverarbeitete); das zweite Exemplum frommer Literatur, die Atala, war bereits 1801 separat publiziert worden. ${ }^{12}$ Die Geschichte der frommen Tochter eines Indianers und einer weißen Christin, die Atala der Muttergottes geweiht und zum Schwur ewiger Jungfräulichkeit gedrängt hatte, endet mit dem Selbstmord Atalas, der der unlösbare Konflikt zwischen dem Schwur und ihrer Liebe zu dem Indianer Schaktas keinen anderen Ausweg lässt.

Zusammen unter anderem mit Jacques-Louis Davids „Krönung Napoleons“, dem Bild, das nur wenig abgemildert die Düpierung des Papstes während der Krönungszeremonie in Notre-Dame memoriert, war in der Pariser Salonausstellung von 1808 ein Gemälde des Davidschülers Anne-Louis Girodet-Trioson zu sehen, der Chateaubriands Novelle zum Anlass nahm, eine „,sentimentale Ikone“ zu malen (Abb. 7). Schaktas und ein Einsiedler tragen die schöne Tote zu Grabe. Die Bildformel, derer sich Girodet für sein Gemälde bediente, ist die traditionelle Bildformel der Grablegung Christi. Die Selbstmörderin war zur Märtyrerin in einem neuen Heiligenbild aufgestiegen, und zum Ort der Verehrung war die Kunstausstellung und das Museum geworden.

Ein deutscher Dichter vollzog noch vor Chateaubriand in einem Roman die Neugeburt des Christentums aus dem Geist der Ästhetik. Ludwig Tiecks Romanfragment Franz Sternbalds Wanderungen von 1798 schildert den Weg eines jungen Malers zum seinem Ideal einer neuen und wahreren christlichen Kunst. Er ist Schüler Albrecht Dürers in Nürnberg; später verlässt er den Meister, um zuerst eine Reise in die Niederlande und dann nach Italien zu unternehmen. Vor seiner Italienreise malt er für die Kirche seines Heimatdorfes ein Bild der Verkündigung Mariä. In der Sonntagsmesse, während der die Gemeinde erstmals das neue Altarbild sehen kann, wird Franz Sternbald von seinem eigenen Werk zutiefst ergriffen.

Franz [...] erstaunte über die Schönheit und rührende Bedeutsamkeit seiner Figuren, sie waren nicht mehr die seinigen, sondern er empfand eine Ehrfurcht, einen andächtigen Schauer vor dem Gemälde. ${ }^{13}$

Seine religiöse Ergriffenheit vor der eigenen Kunstschöpfung mündet in ein Bekenntnis zur Einheit von Kunst und Andacht:

Sternbalds Gemüt ward mit unaussprechlicher Seligkeit angefüllt, er empfand zum ersten Male den harmonischen Einklang aller seiner Kräfte und Gefühle, ihn ergriff und beschirmte der Geist, der die Welt regiert und in Ordnung hält, er gestand es sich deutlich, wie die Andacht der höchste und reinste Kunstgenuß sei, dessen unsere menschliche Seele nur in ihren schönsten und erhabensten Stunden fähig ist. ${ }^{14}$

\footnotetext{
${ }^{10} \mathrm{Vgl}$. Chateaubriand (1879: $313 \mathrm{ff}$.).

${ }^{11}$ Zitiert nach Kindlers Literaturlexikon (1974: 3844).

${ }^{12}$ Vgl. Chateaubriand (1962: 3-82).

13 Tieck (1966: 71).

${ }^{14}$ Tieck (1966: 72).
} 




Abb. 7: Anne-Louis Girodet-Trioson, Das Begräbnis der Atala, Salon von 1808, Paris, Musée du Louvre

Italien wird für Franz Sternbald dann zur großen Gefährdung, schließlich aber der Ort der künstlerischen und religiösen Reife.

In der Nachschrift zum ersten Teil des Romans verwies Tieck auf die im Vorjahr erschienenen Herzensergießungen eines kunstliebenden Klosterbruders Wilhelm Heinrich Wackenroders. Dieses Buch ist fundamental für die neue religiöse Malerei, wie sie das frühe 19. Jahrhundert ins Werk setzen wird. „Ich vergleiche den Genuß der edleren Kunstwerke dem Gebet“", so eine der programmatischen Aussagen. ${ }^{15}$ Wackenroders Buch enthält den „Brief eines jungen deutschen Malers in Rom an seinen Freund in Nürnberg“. Tieck reklamiert in seiner Nachschrift diesen Text für sich; die Forschung schwankt in der Zuschreibung des Textes an Tieck oder an Wackenroder. Bezüglich der Frage nach der neuen ästhetischen Konzeption des Christentums ist signifikant, dass in diesem Brief eine Konversion zum Katholizismus beschrieben wird - eine Konversion bewirkt durch Schönheit und Liebe: durch Schönheit der und Liebe zur Kunst Raffaels, durch Schönheit der und Liebe zur Verlobten und durch die Schönheit der Liturgie. Aus Liebe zu Raffael und zur schönen Marie und erschüttert durch die ästhetische Macht einer lateinischen Messe bekehrt sich der junge Nürnberger Maler vom Luthertum zum Katholizismus:

Franz schwärmt von den ,,verklärten Angesichtern Raffaels“. Hätte er sie schon in Nürnberg sehen können, ,so wäre ich gewiss in meine Knie gesunken und hätte meine ganze

\footnotetext{
${ }^{15}$ Wackenroder (o. J.: 79).
} 
junge Seele in Andacht, Tränen und Anbetung aufgelöst“ “. ${ }^{16}$ Es ist denn auch der Blick der geliebten Marie, deren ,Züge [er] in den besten Gemälden aufgesucht und sie immer bei meinen liebsten Meistern gefunden“, ${ }^{17}$ es ist ihre Bitte an ihn, ,zum alten wahren Glauben zurückzukehren“, ${ }^{18}$ es ist die großartige Architektur des Pantheons in Rom, es ist die Kirchenmusik, und es ist ein Kreuzigungsgemälde, die Franz zu Boden zwingen.

Ich konnte der Gewalt in mir nicht widerstehen: - ich bin nun, teurer Sebastian, zu jenem Glauben hinübergetreten, und ich fühle mein Herz froh und leicht. Die Kunst hat mich allmächtig hinübergezogen, und ich darf wohl sagen, daß ich nun erst die Kunst so recht verstehe und innerlich fasse. ${ }^{19}$

Der letzte Satz fasst alles zusammen. Kunst macht fromm, und nur wer fromm ist, versteht die Kunst und heißt mit Recht Künstler.

Einige Künstler haben diese literarische Konversion, bewirkt durch die Allmacht der Kunst, tatsächlich auch vollzogen. 1813, in Rom, trat Friedrich Overbeck zum Katholizismus über (Abb. 8). Ihm tat es Wilhelm von Schadow nach, derjenige, der später als Direktor so entscheidend die Düsseldorfer Kunstakademie prägen wird. 1814, ein Jahr nach seinem Freund Overbeck, konvertierte Wilhelm von Schadow zum Katholizismus (Abb. 9). Soweit musste man nicht gehen. Schließlich sind Protestanten keine Heiden. Der Maler Julius Schnorr von Carolsfeld vertrat im Kreis der Nazarener die evangelische Position. Auch für ihn stand die Wiederbelebung der Kunst Raffaels gleichermaßen und ungeschieden für die Erneuerung der Kunst und für eine neue Frömmigkeit (Abb. 10, 11). Diese Malergruppe der Nazarener setzte das literarische Künstlerbild, wie es Wackenroder und Tieck konzipiert hatten, in künstlerische Praxis und in gelebtes Künstlertum um. 1806 hatten sich die jungen Akademieschüler Friedrich Oberbeck und Franz Pforr in Wien kennengelernt. Mit Blick auf ihr Ziel einer Erneuerung der religiösen Kunst gründeten sie 1809 nach dem Vorbild christlicher Orden den Lukasbund, und als sie im folgenden Jahr 1810 nach Rom übersiedelten, ließen sie sich denn auch folgerichtig in einem Kloster, dem Kloster von S. Isidoro auf dem Pincio, nieder. In Rom schlossen sich weitere deutsche Maler dem Lukasbund an: unter anderem Peter Cornelius, der spätere erste Direktor der neugegründeten Düsseldorfer Kunstakademie, oder, wie erwähnt, sein Nachfolger im Direktorat der Düsseldorfer Akademie, Wilhelm von Schadow.

\section{Die Psychologisierung der religiösen Erfahrung}

Die Maler Willliam Holman Hunt, John Everett Millais und Dante Gabriel Rossetti sowie zwei weitere bildende Künstler und zwei Literaten gründeten 1848 in London die PreRaphaelite Brotherhood. Auch den Präraffaeliten war die Rückkehr zu früheren, heileren Zeiten der Kunst das erklärte Ziel. Nur gingen sie ein gutes Stück weiter zurück als die Nazarener. War Raffael der unumstrittene künstlerische Held der Nazarener, den sie mit dem deutschen Albrecht Dürer zu verbinden trachteten, so war für die Präraffaeliten Raffael und sein Zeitalter bereits eines der Dekadenz der Kunst. Rückkehr zur Kunst vor Raffael,

\footnotetext{
16 Tieck (1966: 491).

17 Tieck (1966: 491).

18 Tieck (1966: 492).

19 Tieck (1966: 494).
} 


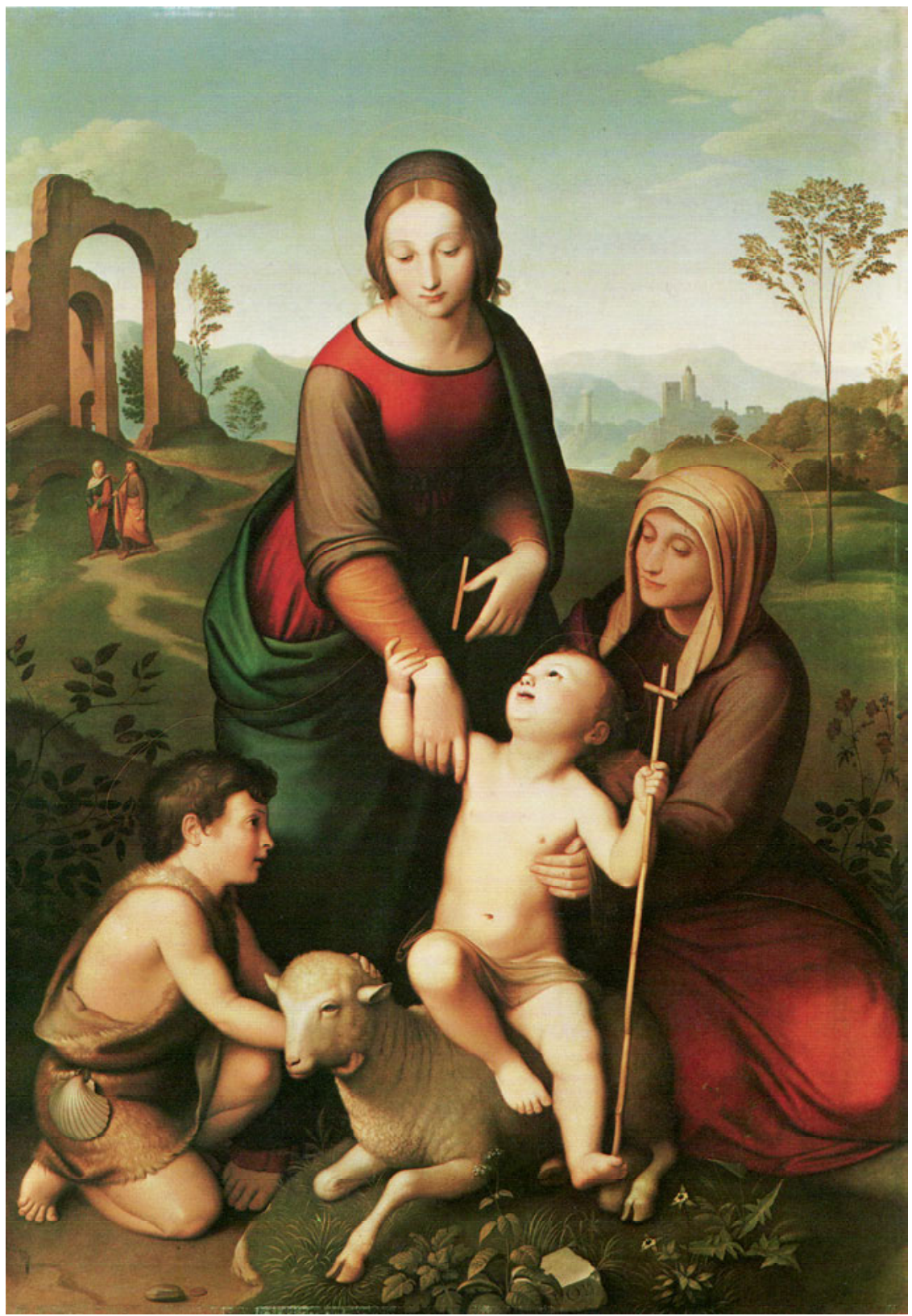

Abb. 8: Johann Friedrich Overbeck, Maria und Elisabeth mit Jesus und Johannes, 1825, München, Neue Pinakothek 


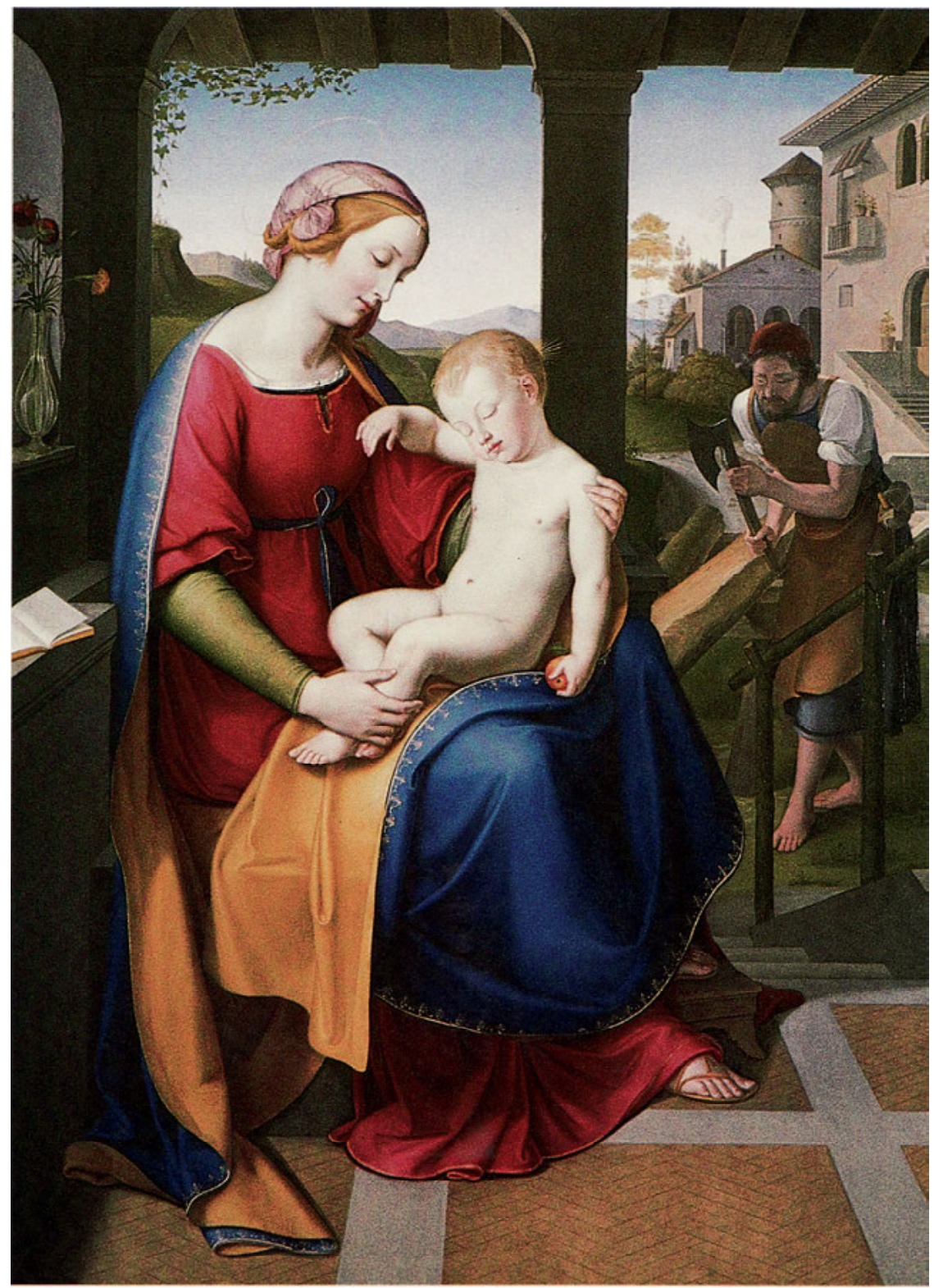

Abb. 9: Wilhelm von Schadow, Die heilige Familie unter dem Portikus, 1819, München, Neue Pinakothek 


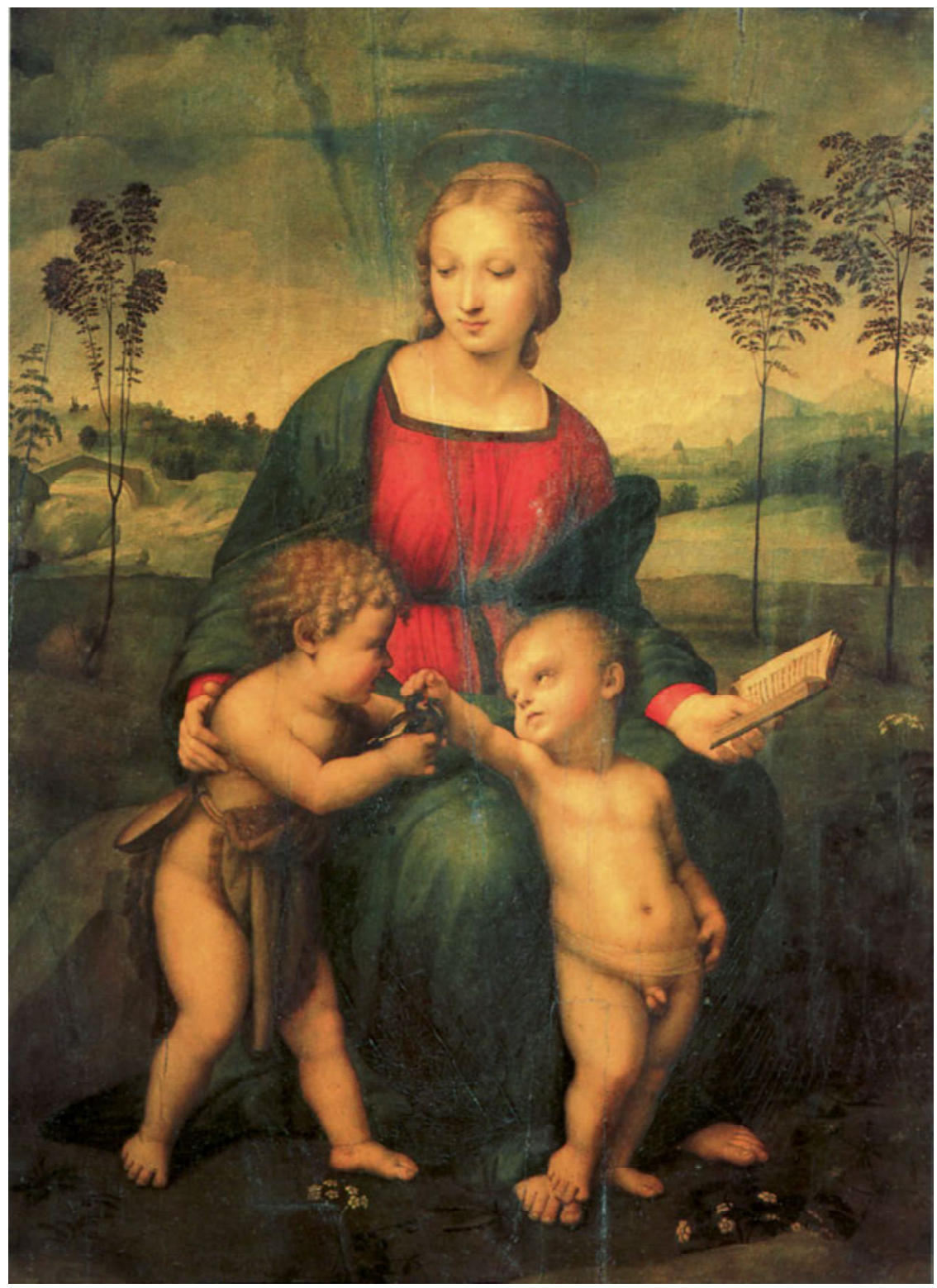

Abb. 10: Raffael, Die Madonna mit dem Stieglitz, 1506, Florenz, Uffizien 


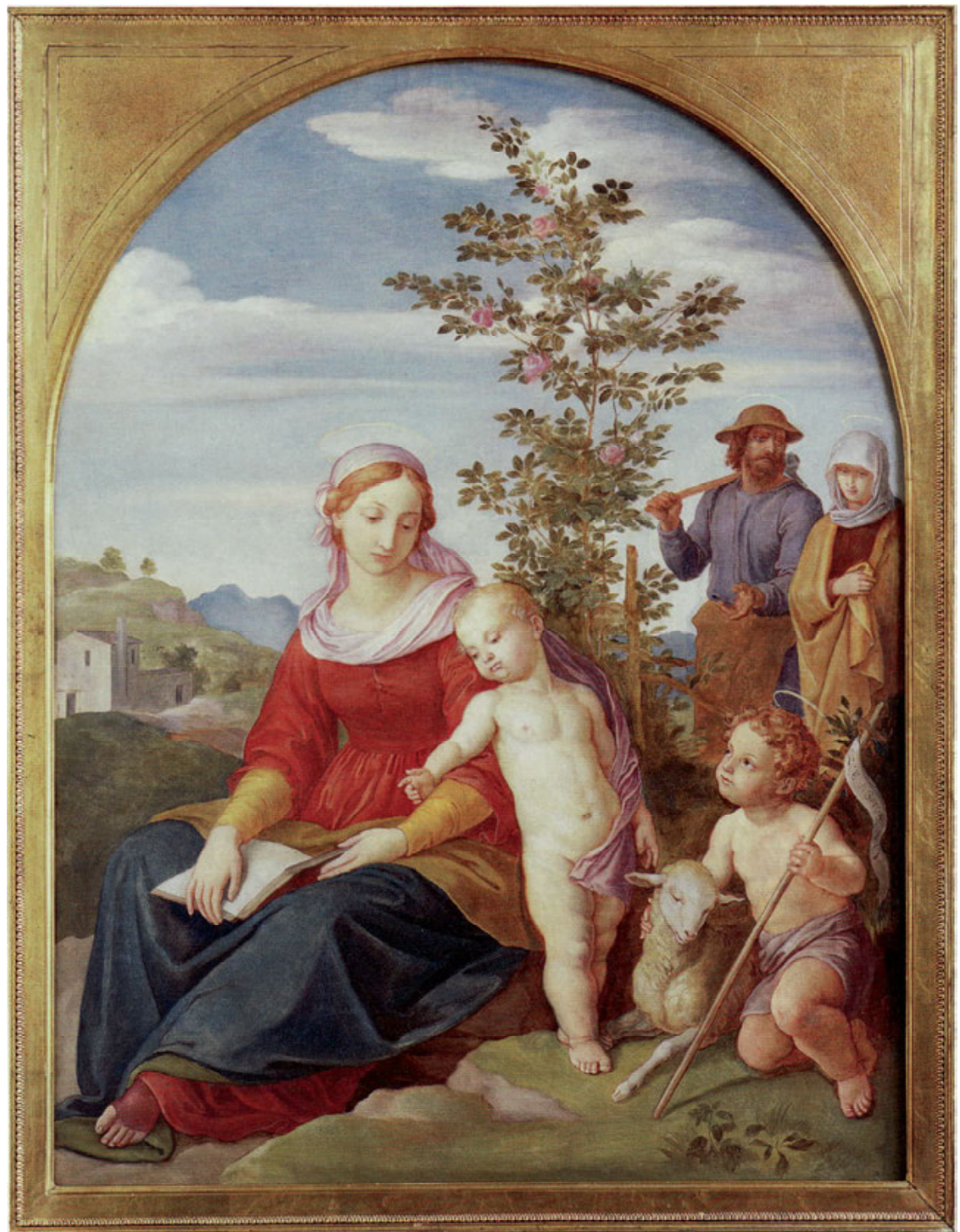

Abb. 11: Julius Schnorr von Carolsfeld, Die heilige Familie, 1843 (?), Chemnitz, Kunstsammlungen 
das war das Programm, und der Name Präraffaeliten sagt dies bereits hinreichend deutlich aus.

Zur Zeit der Gründung der Bruderschaft waren die Londoner Houses of Parliament im Bau (Abb. 12). Im Rahmen der allgemeinen Mittelalterbegeisterung, die im England dieser Jahre herrschte und wofür das neogotische Parlamentsgebäude geradezu programmatisch wurde, steht auch die Gründung der präraffaelitischen Bruderschaft. Daneben war es die Frührenaissance, die jetzt gegen die als zu wenig naiv und zu wenig aufrichtig erachtete Hochrenaissance ausgespielt wurde.

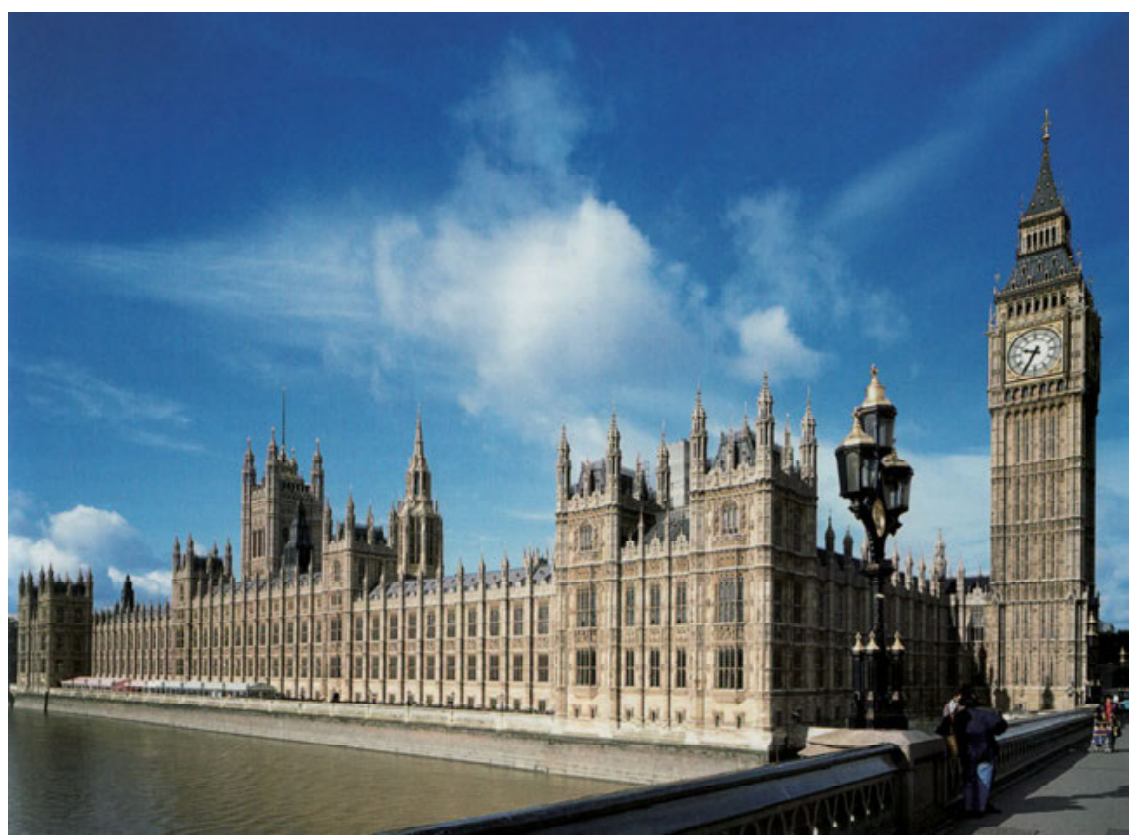

Abb. 12: Charles Barry, Augustus Northmore und Welby Pugin, London, Houses of Parliament, (1835 Wettbewerb) $1839-1860$

Die Erneuerung der religiösen Kunst stand nicht so im Zentrum wie bei den Nazarenern, ein wichtiges Ziel war es für die Präraffaeliten aber sehr wohl. Dank ihrer Begeisterung für die Kunst vor der Hochrenaissance fanden sie in ihren Figurenzeichnungen zu einer neuen Strenge - auch zu einer neuen Strenge im kompositorischen Aufbau. Als Beipiel sei John Everett Millais' „Christus im Haus seiner Eltern“ (Abb. 13) genannt und gezeigt: Die strenge flächenparallele Platzierung der Figuren und der Hauptrequisiten und die forciert symmetrische Anordnung sind anschauliche Entsprechungen für das künstlerische und (ununterscheidbar davon) das religiöse Streben nach Aufrichtigkeit und Naivität.

Hinzu kommt ein neuer Realismus im Zugriff auf die religiöse Überlieferung und eine neue und innovative Ikonografie. Das Gemälde Millets stellt Jesus im Haus seiner Eltern vor Augen. Wir sehen Joseph, den heiligen Zimmermann, bei der Arbeit. An der Bretterwand hängen übliche Zimmermannswerkzeuge: Säge, Leiter, Zange, Nägel, Hammer und 


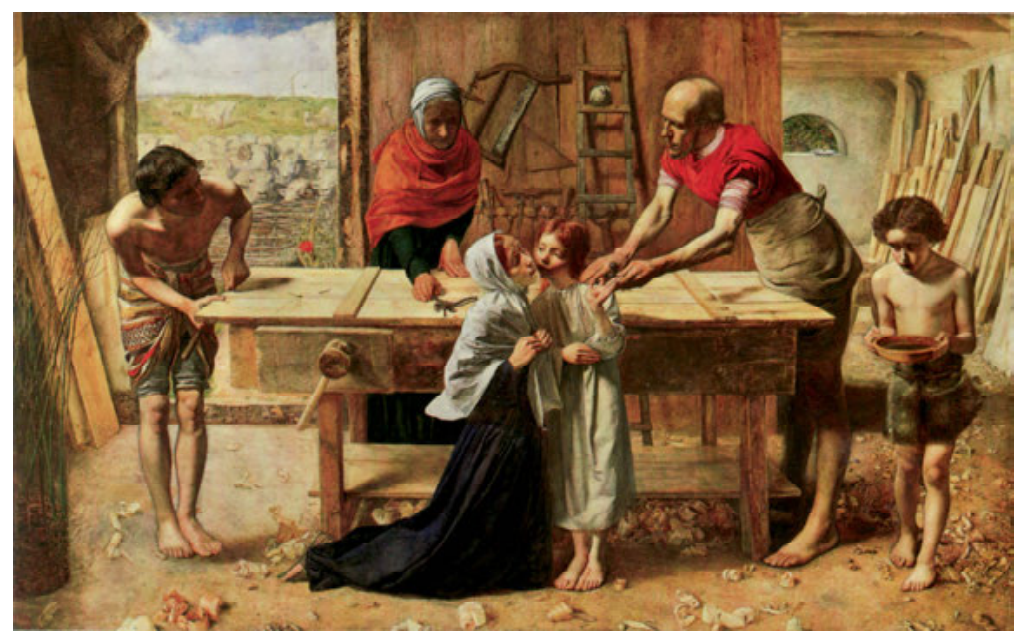

Abb. 13: John Everett Millais, Christus im Haus seiner Eltern, 1849-1850, London, Tate Gallery

ein Dreieckslineal. Aber es hängt hier auch eine kleine Geißel, die man in einer Zimmermannswerkstatt üblicherweise nicht benötigt. Die Geißel macht nur Sinn im Vorausblick auf die Geißelung Christi. Und wenn man sich das klargemacht hat, dann erweisen sich auch einige der genannten Werkzeuge, wie Leiter und Nägel, als Symbole der künftigen Passion. Das Dreieckslineal wird man auf die Dreifaltigkeit beziehen müssen und der Schlitz in der Holzwand, exakt in der Mittelachse, verbindet sich mit dem quer genagelten kleinen Brettchen zu einer Kreuzform. Eine Vorahnung der Passion gibt schließlich die Bilderzählung. Jesus hat als braver Sohn seinem Vater bei der Arbeit geholfen. Dabei verletzte er sich an der linken Handinnenfläche. So schlimm kann die Wunde eigentlich nicht sein, dass sie die tiefste Betrübnis, die die neben Jesus kniende Maria empfindet, rechtfertigen würde. Doch die Muttergottes trauert deshalb, weil ihr im Anblick der verletzten Kinderhand die zukünftigen Wundmale des Gekreuzigten vor dem inneren Auge stehen. Und solches sieht auch der eine Schale tragende Knabe rechts. Sein Pelzkleidchen weist ihn als den noch kleinen Propheten Johannes den Täufer aus, und auch der Sehergabe des kleinen Johannes entgeht nicht der prophetische Charakter der Verletzung des Jesuskindes. Sein unsagbar trauriger Blick aus tief verschattetem Gesicht gibt seinem Empfinden deutlich Ausdruck. Das sind sehr neue Weisen, religiöse Inhalte zu vermitteln, und sie werden vermittelt von Figuren, von sehr individuellen Figuren, in einem durchaus - zumindest auf den ersten Blick - alltäglichen Kontext.

Wie weit die Individualisierung der biblischen Figuren und die Psychologisierung religiöser Erfahrung gehen konnten, verdeutlicht ein kleines Bildchen Dante Gabriel Rossettis (Abb. 14), gemalt zeitgleich mit Millais’ eben beschriebenem Werk. Als Bildtitel („Ecce Ancilla Domini“") wählte Rossetti die demütige Antwort Mariens auf Gruß und Verkündigung des Engels. Die Bilderzählung fügt sich in ein sehr schmales Hochformat, ein Format, das der mädchenhaften Maria kaum Platz lässt, sie einengt und schon so ihr seelisches Bedrängtsein anschaulich macht. Hilflos dem gegenüber, was mit ihr geschieht, drückt sie 


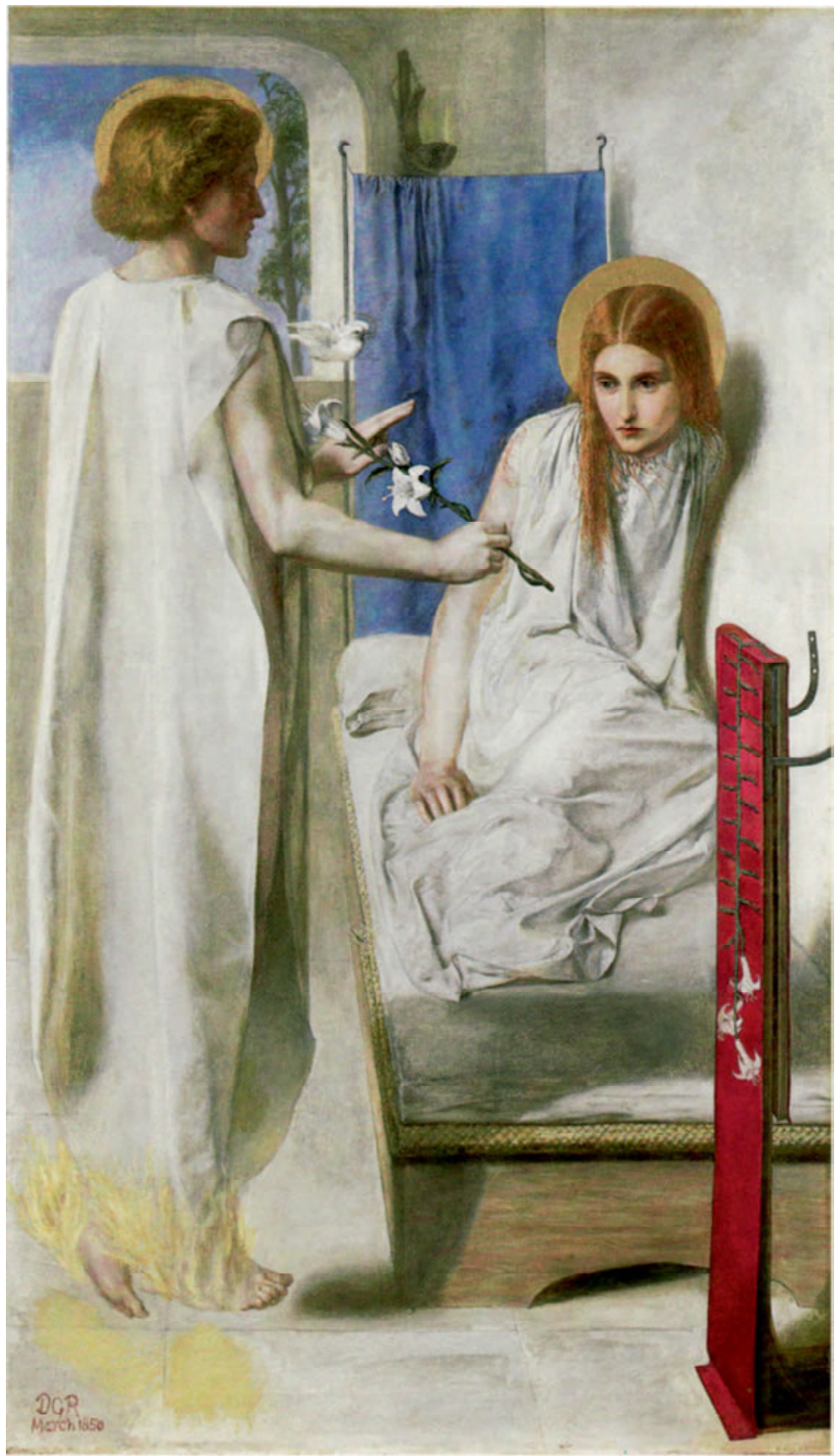

Abb. 14: Dante Gabriel Rossetti, Ecce Ancilla Domini, 1849-1850, London, Tate Gallery 
sich gegen die Wand. Die schmutzig weiße Farbe des Wandanstrichs, das fahle weiße Bettlaken, ihr weißes Nachthemd - all das visualisiert Hilflosigkeit. Das Weiß verweist gemäß traditioneller Farbsymbolik auf die Unschuld der Jungfrau, aber Mariens Unschuld erscheint im Bild als eine bedrohte Unschuld. (Nur beiläufig: Noch nie vorher hatte man die Verkündigungsmaria im Nachthemd gesehen!) Gabriel schwebt zwar als übernatürliches Wesen, aber entgegen der Geschlechtslosigkeit vieler älterer Verkündigungsengel ist Rossettis Engel ein durchaus viriler, gutaussehender junger Mann. Bedrohlich nahe ist er dem Bett der Jungfrau gekommen, und der Lilienstrauß, von dem er Maria den Stil zukehrt, weist in Richtung ihres Geschlechts. Dass die Verkündigung an Maria, jener entscheidende Beginn des Erlösungswerkes, gleichsam als eine traumatische sexuelle Erfahrung sichtbar und die Ergebung Mariens in den göttlichen Willen dabei bildlich als beklemmende Ausweglosigkeit anschaulich wird, das macht das Außerordentliche dieses Bildchens Rossettis aus.

\section{Die Historisierung der religiösen Erfahrung}

Die religiöse Bildkunst der Präraffaeliten steht im Zusammenhang mit einer religiösen Reformbewegung, der sich wichtige Vertreter der anglikanischen Hochkirche anschlossen. Das „Oxford Movement“ verfolgte das Ziel einer Erneuerung der Liturgie. Der Fluchtpunkt dieser Liturgiereform war wie die Kunstreform der Präraffaeliten rückwärts gewandt. Es ging um eine Wiederbelebung des mittelalterlichen Christentums und folgerichtig um eine Annäherung der anglikanischen Liturgie an die katholische. ${ }^{20}$ Dass einer der Hauptvertreter des „Oxford Movement“, John Henry Newman, 1845 zum Katholizismus konvertierte und 1879 Kardinal der katholischen Kirche wurde, ist in diesem geistigen Klima nicht ganz überraschend.

Mit der religiösen Rückwendung zum Mittelalter, wie sie das „Oxford Movement“ vollzog, mit der künstlerischen Rückwendung zur Kunst vor 1500, wie sie sich im Werk der Präraffaeliten ereignete, schließlich mit dem neogotischen Baustil der Houses of Parliament ist die Historisierung von religiöser Erfahrung als eine der Bedingungen der Möglichkeit von moderner religiöser Kunst in den Blick gerückt.

In der zweiten Hälfte des 18. Jahrhunderts setzt das kunstgeschichtliche Phänomen ein, das wir als Historismus bezeichnen. Der Rückgriff auf traditionelle, insbesondere auf gotische Bauformen war gewiss keine exklusive Besonderheit des späteren 18. und 19. Jahrhunderts. Derartige Rückgriffe gab es vom 16. bis zum 18. Jahrhundert regelmäßig, und in England hielten sich gotische Formen vom Spätmittelalter bis zum 18. Jahrhundert fast kontinuierlich. Doch als kunsthistorisch reflektierte, als Aneignung von Geschichte auch ästhetisch gewürdigte und als solche gezielt eingesetzte künstlerische Strategie ist der Historismus mehr als die Fortführung älterer Historismen.

Horace Walpole schrieb mit seinem Castle of Otranto Literaturgeschichte. Dieser 1764 zuerst erschienene Roman, der schauerliche Begebenheiten auf einer mittelalterlichen Burg in Süditalien erzählt, ist der erste Schauerroman der Literaturgeschichte, die erste gothic novel. Dass der Erfinder der gothic novel auch eine entscheidende Rolle bei der historistischen Wiederholung der Gotik spielte, kann nicht überraschen. In Twickenham bei London ließ sich Horace Walpole ab 1749 mit Strawberry Hill eine romantische goti-

${ }^{20}$ Vgl. Metken (1973: 9 f.). 
sche Ritterburg bauen, mit Zinnen, Fialen, auch mit forciert unregelmäßigem Grundriss also mit allem, was für einen gebildeten Engländer des 18. Jahrhunderts als mittelalterlich gelten durfte (Abb. 15). Formen aus gotischen Sakralbauten wurden dabei bedenkenlos in den profanen Zweck überführt: So deckt ein reiches spätgotisches Fächergewölbe, wie es sich in Kapellen findet, die große Galerie, und das Vorbild der gotischen Chorschranken von Old St. Pauls wurde in Strawberry in Bücherschränke übersetzt (Abb. 16, 17).

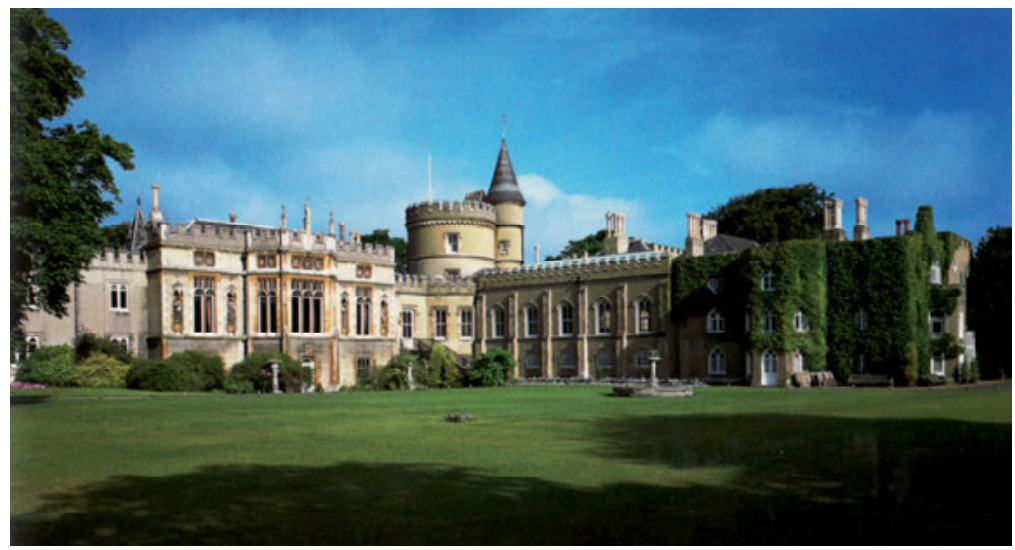

Abb. 15: Twickenham, Strawberry Hill, 1749-1776 (linker Flügel 19. Jahrhundert)

Ab 1760 ließ Walpole das so genannte Kloster anbauen. Das „,sakrale“ Herzstück, die an die Galerie anschließende „Kapelle“, diente als Hauptausstellungsraum von Walpoles Kunstsammlung. Ausgestellt waren Kuriositäten, antike Stücke und Gipsabgüsse der berühmtesten antiken Statuen. In den Kapellennischen sah man den Apoll vom Belvedere, den Antinous, die farnesische Flora und die Mediceische Venus. ${ }^{21}$ Walpoles Aufstellung von antiken Bildwerken, und darunter von immer als ausgesprochen erotisch wahrgenommen Bildwerken wie der Mediceischen Venus in einer neogotischen „Kapelle“, findet ihre Entsprechung in einer erhabenen Imagination, die Walpoles Freund Thomas Gray wenig vorher (am 9. November 1758) William Mason brieflich übermittelte:

If you should led me into a superb Gothic building with a thousand cluster'd pillars, each of them half a mile high [...], and the windows full of red and blue Saints [...]; and I should find the Venus of Medici in person perk'd up in a long niche over the high altar, as naked as ever she was born, do you think it would raise, or damp my devotions? $?^{22}$

1772 stand Johann Wolfgang von Goethe vor der Fassade des Straßburger Münsters (Abb. 18, 19). Er, der an der klassischen Kunst Geschulte, erfuhr ein Offenbarungserlebnis vor dieser gotischen Fassade, die für ihn - irrtümlicher- und bezeichnenderweise - das Beispiel „Deutscher Baukunst“ schlechthin war.

\footnotetext{
${ }^{21}$ Vgl. Dobai (1974: 261).

22 Zitiert nach Dobai (1974: 202 f.). Übersetzung: „Wenn Sie mich in ein grandioses gotisches Bauwerk führten, das errichtet ist mit Tausenden von Bündelpfeilern, von denen jeder eine halbe Meile hoch ist [...]; die Glasfenster voll mit roten und blauen Heiligenfiguren [...]; und ich sähe die Venus von Medici selbst in einer hohen Nische über dem Hochaltar stehen, so nackt, wie sie auf die Welt gekommen ist was meinen Sie: Würde das meine Frömmigkeit steigern oder dämpfen?“”
} 


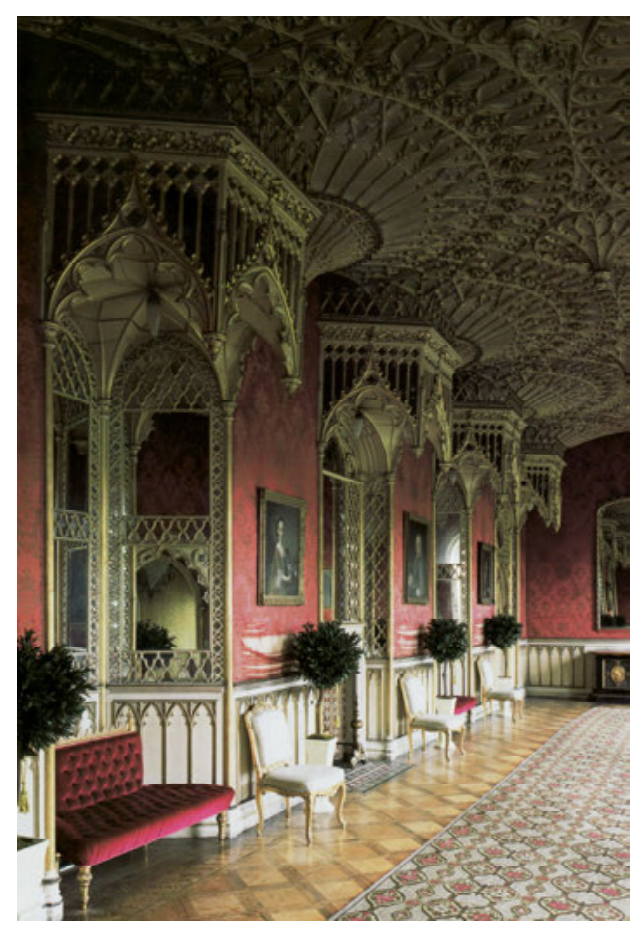

Abb. 16: Twickenham, Strawberry Hill, Große Galerie, 1759-1763

Als ich das erste Mal nach dem Münster ging, hatt' ich den Kopf voll allgemeiner Erkenntnis guten Geschmacks. Auf Hörensagen ehrt' ich die Harmonie der Massen, die Reinheit der Formen, war ein abgesagter Feind der verworrenen Willkürlichkeiten gotischer Verzierungen. [...] Mit welcher unerwarteten Empfindung überraschte mich der Anblick, als ich davor trat! Ein ganzer, großer Eindruck füllte meine Seele, den, weil er aus tausend harmonierenden Einzelheiten bestand, ich wohl schmecken und genießen, keineswegs aber erkennen und erklären konnte. Sie sagen, daß es also mit den Freuden des Himmels sei, und wie oft bin ich zurückgekehrt, diese himmlisch-irdische Freude zu genießen, den Riesengeist unsrer älteren Brüder in ihren Werken zu umfassen. ${ }^{23}$

Auch bei Goethe also die Verschmelzung von Transzendenz und Ästhetik. Und deutlicher wird das noch in einem drei Jahre später verfassten Text, der die Verbindung von religiöser und ästhetischer Andacht schon im Titel anspricht: „Dritte Wallfahrt nach Erwins Grabe im Juli 1775“. Den Baumeister des Straßburger Münsters - wir wissen, dass er nur einer der Baumeister des Münsters war -, Erwin von Steinbach, nannte Goethe in diesem Text den „heilige[n] Erwin“. Und er sprach vor dem Münster sein „Gebet“, das ein ästhetisches Glaubensbekenntnis ist: „Du bist Eins und lebendig, gezeugt und entfaltet, nicht zusammengetragen und geflickt [...]“. ${ }^{24}$

\footnotetext{
${ }^{23}$ Goethe $\left({ }^{9} 1981\right.$ b: 10 f. $)$.

${ }^{24}$ Goethe $\left({ }^{9}\right.$ 1981a: 28$)$.
} 


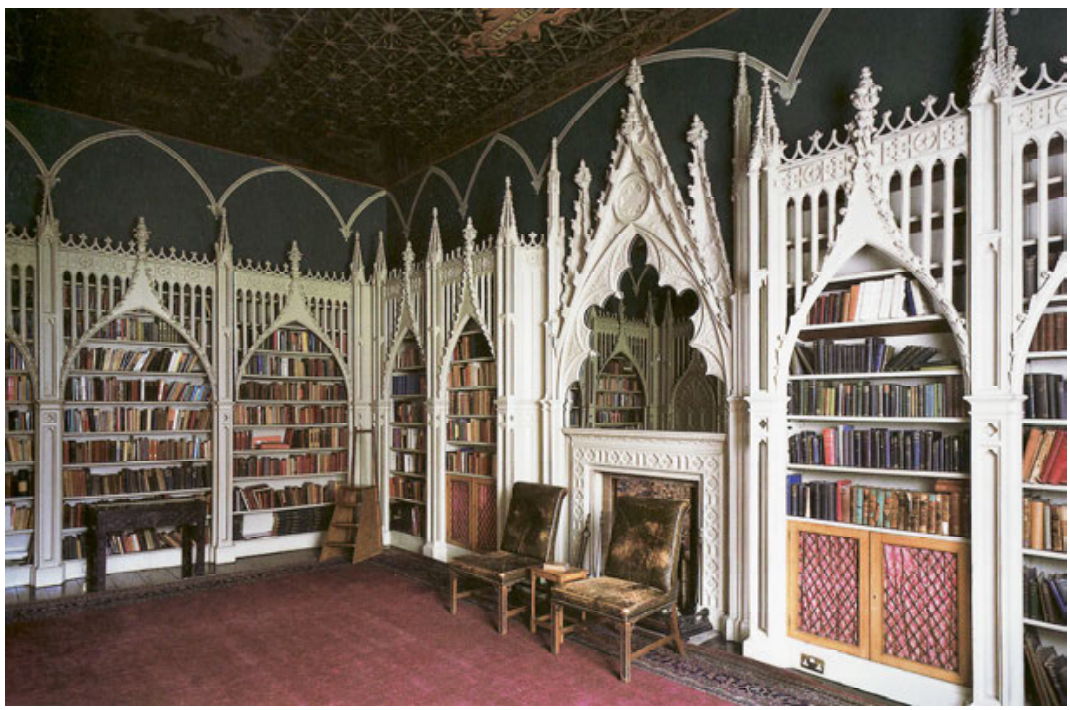

Abb. 17: Twickenham, Strawberry Hill, Bibliothek, 1754

\section{Resümee}

Die alte und nun wieder ganz neue Erfahrung von Armut und Verfolgung der christlichen Gemeinde, das neue Bündnis von Frömmigkeit und Kunst, die Psychologisierung und die Historisierung von Religiosität - diese Charakteristika, die sich gewiss ergänzen, in jedem Fall aber präzisieren ließen, haben gemeinsame Schnittmengen. Es waren innovative Ansätze, es waren moderne Ansätze. Eine derartige Aussage setzt sich allerdings in Widerspruch zu fast allen, die die moderne sakrale Kunst im 20. Jahrhundert publizistisch, institutionell oder als Künstler vorangetrieben und ins Werk gesetzt haben. Nazarenertum, Präraffaeliten, Historismus wurden zu Schimpfwörtern bei denjenigen, die sich für eine der Moderne angemessene Sakralkunst eingesetzt hatten, und noch für den überwiegenden Teil der neueren Sekundärliteratur ist die Distanzierung vom historistischen Stilkleid und von der Gefühlskultur der nazarenischen und präraffaelitischen Bildkunst die Bedingung der Möglichkeit einer neuen, einer modernen christlichen Kunst.

Diese Abgrenzung zu beschreiben ist eine wichtige Aufgabe der Kunstgeschichte. Auch und gerade wir, die wir heute die Aversion gegen das 19. Jahrhundert nicht mehr teilen können, die wir keine Vorbehalte mehr gegen die Malerei Overbecks oder Rossettis haben, wir, die wir inzwischen gegen bornierte Kommunalpolitiker um den Erhalt historistischer Bauten streiten, wir müssen die Ablehnung der religiösen Kunst des 19. Jahrhunderts durch die Schöpfer christlicher Architektur und Bildkunst im 20. Jahrhundert zumindest als historisches Faktum ernst nehmen. Es verdient aber auch ernst genommen, dass gleichwohl die im späten 18. und im 19. Jahrhundert gewonnenen Positionen zur Ausbildung einer modernen Frömmigkeit und damit entscheidend zur Ausbildung einer modernen Sakralkunst beigetragen haben. Und auch wenn die Kluft zwischen dem 19. Jahrhundert und den Neuerern des 20. Jahrhunderts auf den ersten Blick unüberwindbar scheint: Es füh- 


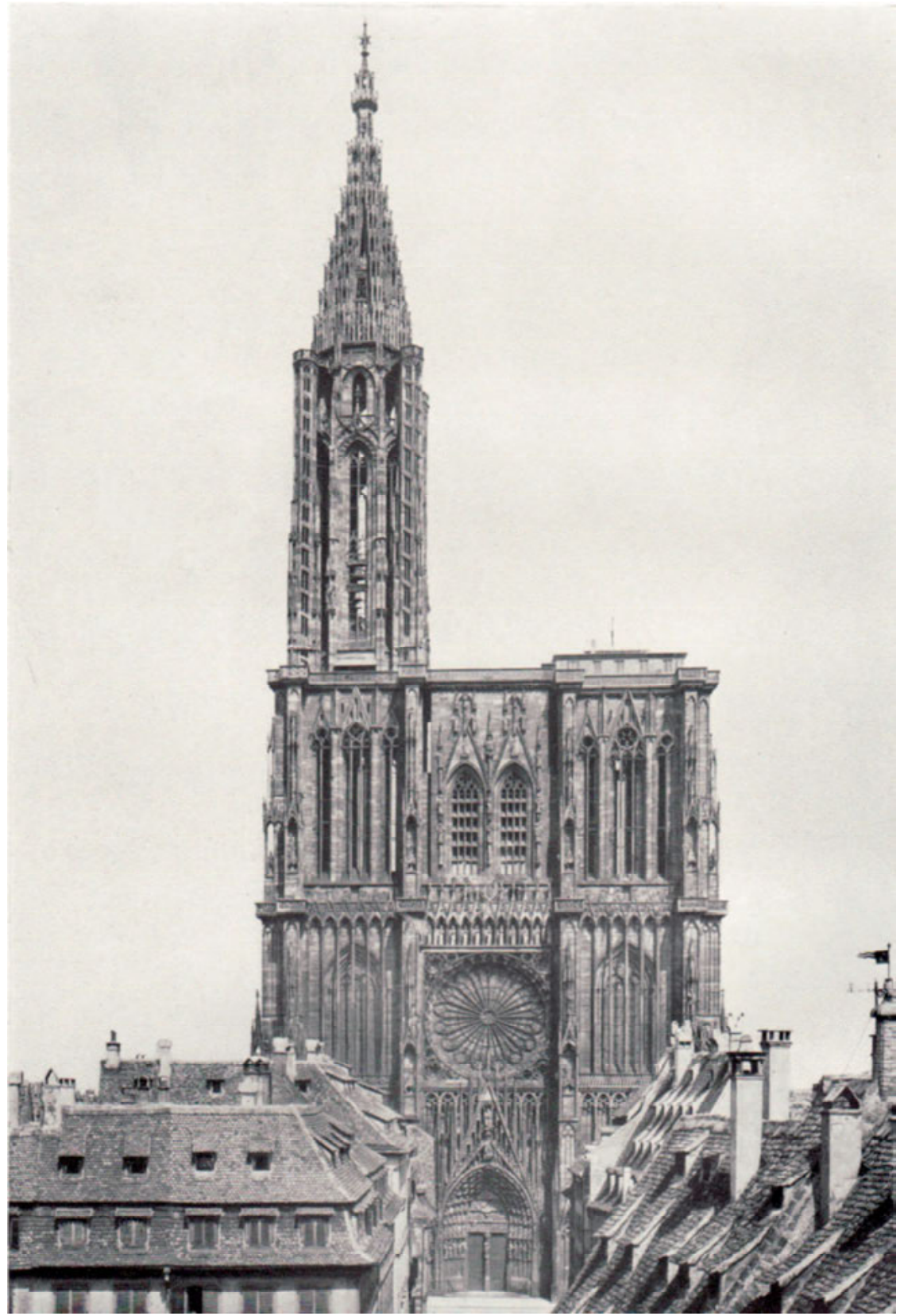

Abb. 18: Straßburg, Münster, Fassade, 1277-1439 


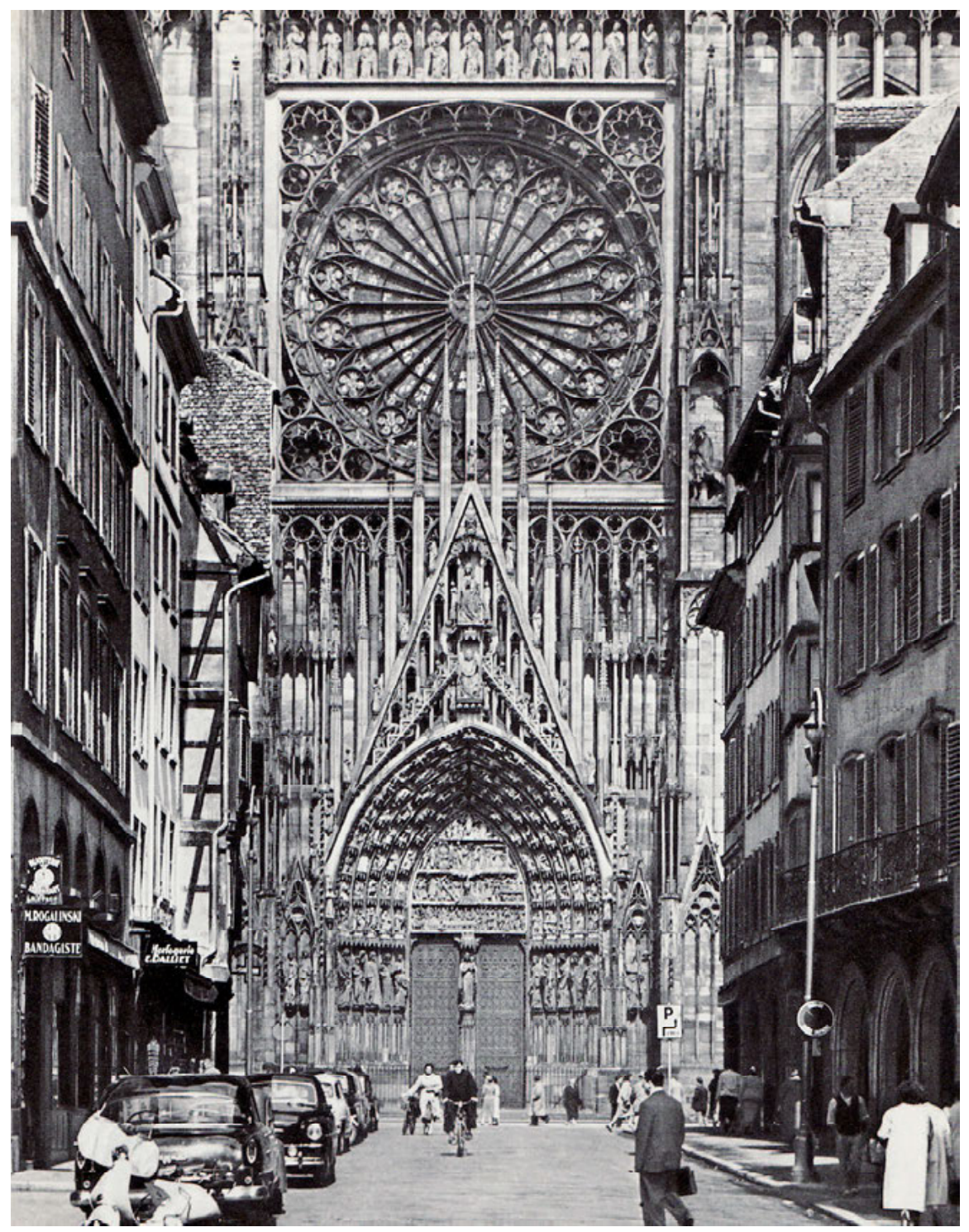

Abb. 19: Straßburg, Münster, Fassade, 1277-1439

ren Verbindungsstege vom 19. Jahrhundert zur Avantgarde des 20. Jahrhunderts - mehr Verbindungsstege, als es den meisten Historikern auf dem Gebiet der modernen Sakralkunst bewusst war, und mehr, als vielen progressiven Kirchenarchitekten und Schöpfern religiöser Bilder lieb war. 


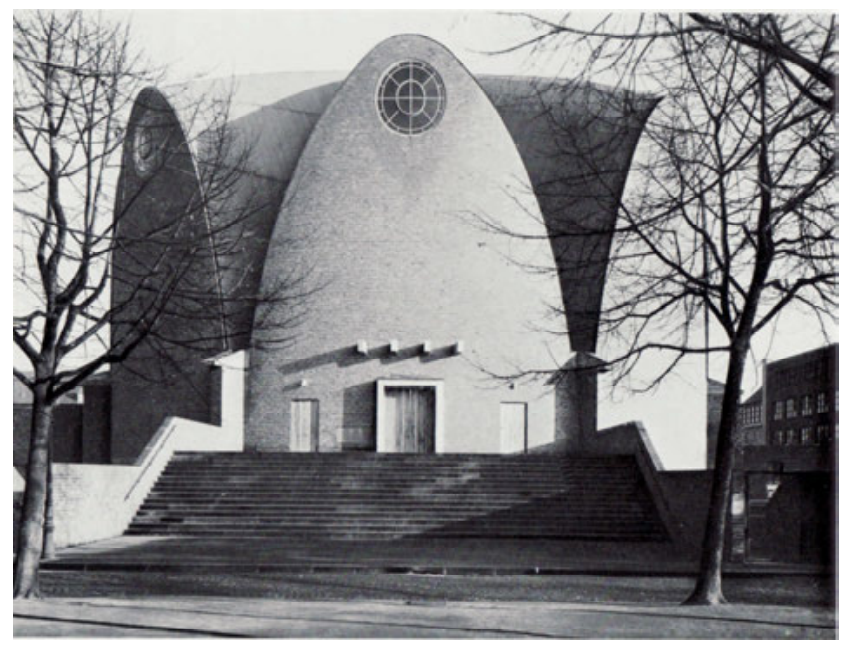

Abb. 20: Dominikus Böhm, Köln-Riehl, St. Engelbert, 1930-1932

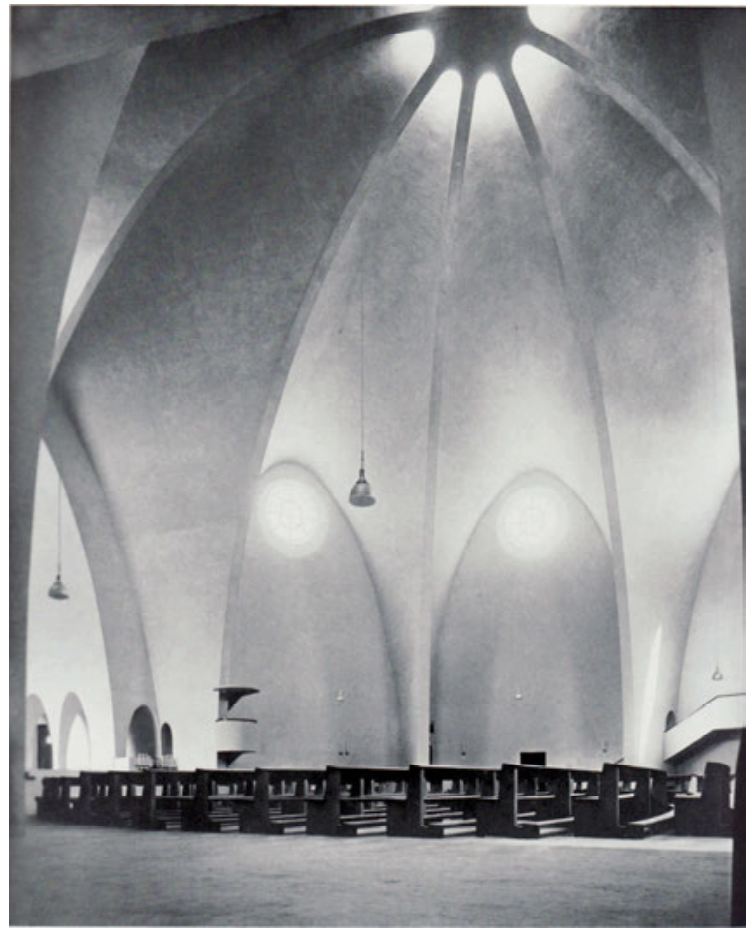

Abb. 21: Dominikus Böhm, Köln-Riehl, St. Engelbert, 1930-1932 


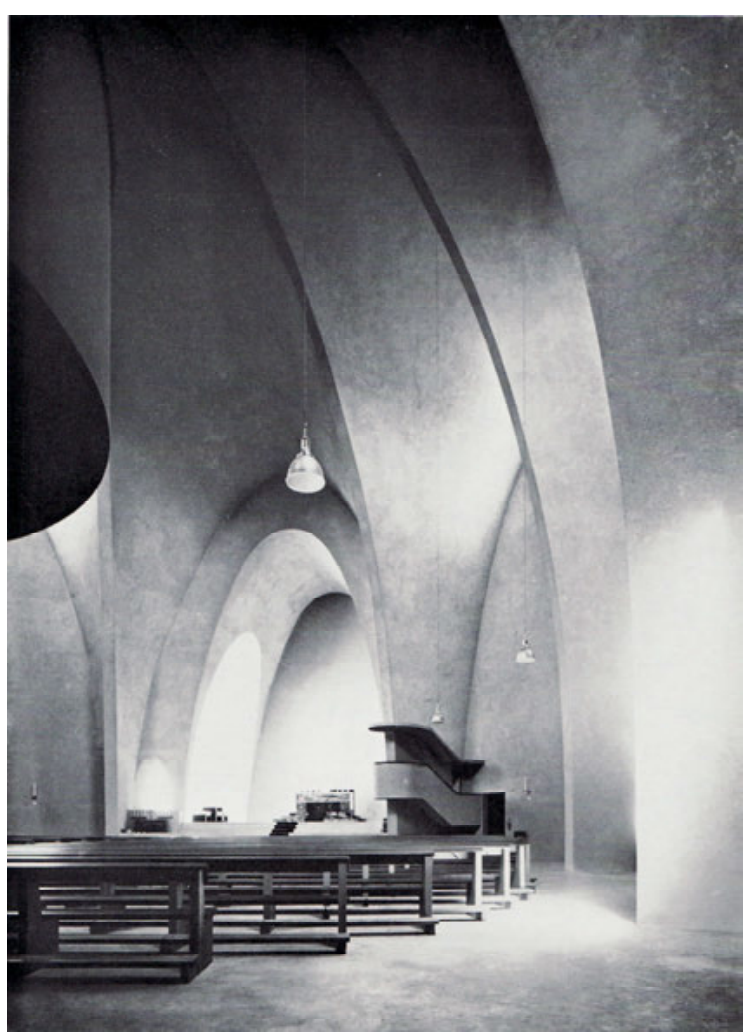

Abb. 22: Dominikus Böhm, Köln-Riehl, St. Engelbert, 1930-1932

Dazu ein abschließendes Beispiel: St. Engelbert in Köln-Riehl - nahe dem Kölner Zoo ist ein Hauptwerk des katholischen Kirchenbaumeisters Dominikus Böhm (Abb. 20, 21). Dieser 1932 vollendete Kirchenbau bedeutet für die Erzdiözese Köln, ja für die Weltkirche, einen Markstein in der Geschichte des modernen Sakralbaus. Gewölbe, die Parabolform haben und bis zum Boden herabgezogen sind, schaffen einen ungemein suggestiven Raumeindruck, in dem man eine geradezu paradigmatisch expressionistische Architektur erkannte. Der Architekt selbst war mit dieser stilgeschichtlichen Zuweisung keinesfalls einverstanden. Vehement verwahrte sich Dominikus Böhm dagegen, als Expressionist klassifiziert zu werden. ${ }^{25}$ Demgegenüber bekannte sich Böhm explizit zu einer historistischen Formsprache. Um dem Vorwurf der Traditionslosigkeit zu begegnen, verwies Böhm bezüglich seines Kirchenbaus in Köln-Riehl ausdrücklich auf das Vorbild der spätantiken und mittelalterlichen Kunst. Die „herrlichen Vorbilder mittelalterlicher Baukunst“ führte Böhm zu seiner Rechtfertigung an. Er nannte bezüglich der gewählten Zentralbauform unter anderem die Hagia Sophia in Istanbul, und wie selbstverständlich bezog er sich auf

${ }^{25}$ Vgl. Brülls (1994: 113). 
das Vorbild der rheinischen Romanik. Die geplante Kuppel sei ,eine großzügige Weiterentwicklung der heimischen Kuppelformen“. ${ }^{26}$

Was Böhms epochalen Kirchenbau von den genannten Bauten der Spätantike und des Mittelalters auch und vor allem unterscheidet, ist der forcierte Versuch, durch künstlerische Mittel Stimmungen zu evozieren. Eben so aber ging das 19. Jahrhundert mit den historischen Stilformen um. Stile waren zu Stimmungsträgern geworden. In fast schon beklemmender Weise versucht Böhm, in diesem Sakralbau mit architektonischen Mitteln direkt auf die Psyche des Gläubigen einzuwirken. So abwegig es erscheinen mag, zwei so gegensätzliche Phänomene, das befremdliche Verkündigungsbild Dante Gabriel Rossettis (Abb. 14) und den Innenraum von St. Engelbert (Abb. 22), gemeinsam zu nennen: Gemeinsam ist beiden, dass hier Schichten in der Psyche angesprochen werden, für die sich gewiss Sigmund Freud zuständig gefühlt hätte - Schichten, die die Konventionen religiöser Erfahrung und Empfindung auf Elementareres hin über- oder, wenn man will, unterschreiten. Und wenn man dann erfährt, dass Dominikus Böhm selbstverständlich davon ausging, dass man, um gute Kirchen bauen zu können, auch ein frommer Mensch zu sein habe (,Ich baue, was ich glaube“), dann stellen sich auch Zusammenhänge her zu einem Verhältnis von Kunst und Frömmigkeit, das zurückreicht bis zu Goethes heiligem Erwin, Tiecks Franz Sternbald und den Nazarenern. In jedem Fall sollte, nachdem lange das Trennende fast ausschließlich in den Blick genommen wurde, in Zukunft auch das Verbindende zwischen der Sakralkunst des 20. Jahrhunderts und der seines Vorgängerjahrhunderts ernsthafter bedacht werden.

\section{Literatur}

BARTNING, Otto (1958). Vom Raum der Kirche. Aus Schriften und Reden ausgewählt und eingeleitet von Alfred Siemon. Bramsche bei Osnabrück. (Baukunst des 20. Jahrhunderts. Quellen und Monographien, Forschungen und Berichte; 2)

BRÜLlS, Holger (1994). Neue Dome. Wiederaufnahme romanischer Bauformen und antimoderne Kulturkritik im Kirchenbau der Weimarer Republik und der NS-Zeit. Berlin und München.

Chateaubriand, François René De (1879). Le Génie du Christianisme (1802). Paris.

Chateaubriand, François René DE (1962). „Atala“ (1801), in: François René DE ChateaubriAND. Atala, René. Stuttgart, 3-82.

DEHIO, Georg ( $\left.{ }^{2} 1941\right)$. Das Strassburger Münster. München.

Diderot, Denis (1875). „Rêve de d'Alembert“ (1769), in: Denis Diderot. Oeuvres completes. Herausgegeben von Jules AssÉZAT und Maurice TourneuX. Bd. II. Paris, 122-181.

Die 48 Notkirchen in Deutschland (1949). Heidelberg.

Die Nazarener. Katalog der Ausstellung, Frankfurt am Main, Städtische Galerie im Städelschen Kunstinstitut (1977). Frankfurt am Main.

DoBAI, Johannes (1974). Die Kunstliteratur des Klassizismus und der Romantik in England. Bd. I: 1700-1750. Bern.

Dominikus Böhm (1962). München und Zürich.

FUSSBRoICH, Helmut (2005). Architekturführer Köln. Sakralbauten nach 1900. Köln.

GoETHE, Johann Wolfgang von $\left({ }^{9} 1981 \mathrm{a}\right)$. „Dritte Wallfahrt nach Erwins Grabe im Juli $1775^{\circ}$, in: Johann Wolfgang VON GoETHE. Goethes Werke, Hamburger Ausgabe. Bd. XII: Schriften zur Kunst. Schriften zur Literatur. Maximen und Reflexionen. Textkritisch durchgesehen von

\footnotetext{
${ }^{26}$ Brülls (1994: 111 f.).
} 
Erich TRUnZ und Hans Joachim SCHRIMPF. Kommentiert von Herbert vON EINEM und Hans Joachim SCHRIMPF. München, 28-31.

GoETHE, Johann Wolfgang VON $\left({ }^{9} 1981 b\right)$. „Von deutscher Baukunst“ (1772), in: Johann Wolfgang von Goethe. Goethes Werke, Hamburger Ausgabe. Bd. XII: Schriften zur Kunst. Schriften zur Literatur. Maximen und Reflexionen. Textkritisch durchgesehen von Erich TRUNZ und Hans Joachim SCHRIMPF. Kommentiert von Herbert vON EINEM und Hans Joachim SCHRIMPF. München, 7-15.

Gowing, Lawrence (1994). Die Gemäldesammlung des Louvre. Mit einer Einleitung von Michel LACLOTTE (1987 engl.). Köln.

Gross, Werner (1969). Gotik und Spätgotik. Ein Umschau-Bildsachbuch. Frankfurt am Main.

Hollein, Max und Christa Steinle (Hrsg., 2005). Religion Macht Kunst. Die Nazarener. Katalog der Ausstellung, Frankfurt am Main, Schirn Kunsthalle. Köln.

JeAn Paul (1987). Siebenkäs. Blumen-, Frucht- und Dornenstücke oder Ehestand, Tod und Hochzeit des Armenadvokaten F. St. Siebenkäs im Reichsmarktflecken Kuhschnappel (1796/1817). Mit einem Nachwort von Hermann HEsSE. Frankfurt am Main.

Kindlers Literatur Lexikon 9 (1974). München.

KÖRNER, Hans (2008). „Nach 1945. Weiterentwicklung oder Neubeginn im modernen Kirchenbau?", in: Hans KöRNER und Jürgen WIENER (Hrsg.). Frömmigkeit und Moderne. Kirchenbau des 20. Jahrhunderts an Rhein und Ruhr, Katalog der Ausstellung, Neuss, Clemens-Sels-Museum. Essen, 35-54.

LA MetTRIE, Julien Offray DE (1774). „L'homme machine“ (1748), in: Julien Offray DE LA METTRIE. Oeuvres philosophiques. Bd. III. Amsterdam.

Lexikon der Düsseldorfer Malerschule, Bd. III (1998). München.

MetKen, Günter (1973). „Die zornigen Viktorianer“, in: Präraffaeliten. Katalog der Ausstellung, Baden-Baden, Staatliche Kunsthalle. Baden-Baden, 9-12.

Oberhuber, Konrad (1999). Raffael. Das malerische Werk. München u. a.

PARRIS, Leslie (Hrsg., ${ }^{3}$ 1996). The Pre-Raphaelites. London.

STEFFAnN, Emil (1980). „Können wir noch Kirchen bauen?“ (1958), in: Gisberth HüLSMANN et al. (Hrsg.). Emil Steffann. Katalog der Ausstellung. Bielefeld, Kunsthalle, 104-108.

TIECK, Ludwig (1966). Franz Sternbalds Wanderungen. Eine altdeutsche Geschichte (1798). Berlin.

Toman, Rolf (Hrsg., 2000). Klassizismus und Romantik. Architektur Skulptur, Malerei, Zeichnung. 1750-1848. Köln.

WACKENRODER, Wilhelm Heinrich (o. J.). „Herzensergießungen eines kunstliebenden Klosterbruders“ (1797), in: Wilhelm Heinrich WACKENRODER. Werke und Briefe. Berlin, 7-131.

\author{
Abbildungsnachweis \\ Abb. 1, 2: Archiv des Autors \\ Abb. 3, 4: Die 48 Notkirchen in Deutschland (1949: o. S.) \\ Abb. 5: Fußbroich (2005: 227) \\ Abb. 6: Archiv des Autors \\ Abb. 7: Gowing (1994: 634) \\ Abb. 8: Die Nazarener (1977: 143) \\ Abb. 9: Lexikon der Düsseldorfer Malerschule (1998: 181) \\ Abb. 10: Oberhuber (1999: 59) \\ Abb. 11: Hollein und Steinle (2005: 196) \\ Abb. 12: Toman (2000: 35)
}


Abb. 13, 14: Parris $\left({ }^{3} 1996: 79\right)$

Abb. 15-17: Toman (2000: 37, 26, 27)

Abb. 18: Dehio ( ${ }^{2}$ 1941: Abb. 1)

Abb. 19: Gross (1969: 91)

Abb. 20-22: Dominikus Böhm (1962: 273, 276, 277) 